\title{
Heterogeneous Fenton-Like Catalytic Degradation of 2,4-Dichlorophenoxyacetic Acid by Nano-Scale Zero-Valent Iron Assembled on Magnetite Nanoparticles
}

\author{
Xiaofan $\mathrm{Lv}^{1} \mathbb{1}$, Yiyang $\mathrm{Ma}^{2}$, Yangyang $\mathrm{Li}^{3}$ and Qi Yang ${ }^{1, *}$ \\ 1 Beijing Key Laboratory of Water Resources \& Environmental Engineering, \\ China University of Geosciences (Beijing), Beijing 100083, China; bh79858@sina.com \\ 2 Institute of Environmental Engineering \& Nano-Technology, \\ Tsinghua Shenzhen International Graduate School, Tsinghua University, Shenzhen 518055, China; \\ shelfunfun@yeah.net \\ 3 Beijing Que Chen Architectural Design Consulting Co., Ltd., Beijing 100038, China; 3005160002@cugb.edu.cn \\ * Correspondence: yq@cugb.edu.cn; Tel.: +86-(010)-8232-3917
}

Received: 27 August 2020; Accepted: 15 October 2020; Published: 18 October 2020

check for updates

\begin{abstract}
Fe}^{0} @ \mathrm{Fe}_{3} \mathrm{O}_{4}$ nanoparticles with dispersibility and stability better than single nano zero-valent iron (nZVI) were synthesized and combined with hydrogen peroxide to constitute a heterogeneous Fenton-like system, which was creatively applied in the degradation of 2,4-dichlorophenoxyacetic acid (2,4-D). The effects of different reaction conditions like $\mathrm{pH}$, hydrogen peroxide concentration, temperature, and catalyst dosage on the removal of 2,4-D were evaluated. The target pollutant was completely removed in $90 \mathrm{~min}$; nearly $66 \%$ of them could be mineralized, and the main intermediate product was 2,4-dichlorophenol. Synergistic effects between nZVI and $\mathrm{Fe}_{3} \mathrm{O}_{4}$ made the 2,4-D degradation efficiency in the $\mathrm{Fe}^{0} @ \mathrm{Fe}_{3} \mathrm{O}_{4} / \mathrm{H}_{2} \mathrm{O}_{2}$ system greater than in either of them alone. More than a supporter, $\mathrm{Fe}_{3} \mathrm{O}_{4}$ could facilitate the degradation process by releasing ferrous and ferric ions from the inner structure. The reduction of 2,4-D was mainly attributed to hydroxyl radicals including surface-bound $\cdot \mathrm{OH}$ and free $\cdot \mathrm{OH}$ in solution and was dominated by the former. The possible mechanism of this $\mathrm{Fe}^{0} @ \mathrm{Fe}_{3} \mathrm{O}_{4}$ activated Fenton-like system was proposed.
\end{abstract}

Keywords: 2,4-dichlorophenoxyacetic acid; nano-scale zero-valent iron; magnetite; heterogeneous Fenton-like system; hydroxyl radicals

\section{Introduction}

2,4-dichlorophenoxyacetic acid (2,4-D) is a white powdery crystal; it is corrosive, slightly soluble in water, and easily soluble in most organic solvents [1]. Among phenoxyl herbicides, 2,4-D is one of the most widely used as a plant growth regulator, for lawn care, and for broadleaf weeding of corn, sugarcane, sorghum, and other crops [2]. As an endocrine disruptor with strong biological toxicity, it can enter the human body through inhalation, ingestion, and dermal contact [3]. Exposure to 2,4-D may cause the decline of insulin secretion and immunity, bringing damage to kidneys, liver, muscles, and the central nervous system. After accumulating to a certain concentration in the body, 2,4-D may induce abnormality, gene mutation, or cancer; its presence poses serious threat to humans and other life in nature [4]. At the same time, the low volatility and refractory properties of 2,4-D make it easy to migrate to groundwater by leaching during its production and use, causing persistent environmental pollution [5]. Therefore, remediation of 2,4-D polluted water has become an urgent problem of aquatic environment. 
Advanced oxidation processes (AOPs) are some of the effective remediation methods for reducing organic pollutants in contaminated soils or groundwater. The contribution of AOPs is to introduce a high oxidation potential source to produce the primary oxidant species, hydroxyl radicals $(\cdot \mathrm{OH})$, which react rapidly and unselectively with most organic compounds. Many AOPs have been developed and investigated to mineralize 2,4-D in aqueous solutions [6,7].

As one of the most widely used AOPs, Fenton oxidation has shown significant effects on the remediation of organic pollutants in contaminated soils or groundwater including 2,4-D.Traditional Fenton technology has its effects by utilizing $\mathrm{Fe}^{2+}$ to catalyze the decomposition of hydrogen peroxide to generate radicals like the hydroxyl radical, which can react with most organic compounds unselectively and complete the reduction of target pollutants rapidly [8]. For the high efficiency, non-toxicity, and easy operation, it has been successfully applied to the treatment of many kinds of organic wastewater. Nevertheless, the high operating cost, limited optimum $\mathrm{pH}$ range, and difficulties in recycling ferrous catalysts restrict the large-scale application of Fenton technology $[9,10]$. To overcome these disadvantages, many researchers use heterogeneous or homogeneous catalysts like $\mathrm{Fe}^{3+}, \mathrm{Cu}^{2+}$, pyrite, and some zero-valent metals instead of $\mathrm{Fe}^{2+}$ to establish Fenton-like processes to enhance the remediation effect [11-13]. Among them, nano zero-valent iron (nZVI) has received great attention for its large specific surface area, high permeability, good reactivity, easy accessibility, and low cost [14-16]. However, the high interfacial energy and magnetic and gravitational forces make it easily agglomerate. Meanwhile, the formation of passive shells caused by the oxidation of water or oxygen in surrounding media will hinder the further reaction of inner $\mathrm{Fe}^{0}$ and decrease electron transfer $[17,18]$.

In our previous research, a complex catalyst with nZVI particles attached on the surface of $\mathrm{Fe}_{3} \mathrm{O}_{4}$ was prepared and successfully applied to the reductive degradation of carbon tetrachloride [19]. Introducing $\mathrm{Fe}_{3} \mathrm{O}_{4}$ nanoparticles (NPs) as the supporter could help to overcome the aggregation and passivation problems of nZVI; the magnetic properties make nZVI tightly attracted to the surface of $\mathrm{Fe}_{3} \mathrm{O}_{4}$, thereby optimizing the problems associated with separating the nanomaterial and stabilizing the reaction system. It is noteworthy that the characteristics of nZVI and magnetite determine that the $\mathrm{Fe}^{0} @ \mathrm{Fe}_{3} \mathrm{O}_{4} \mathrm{NPs}$ can complete the degradation of chlorinated organic pollutants through both the reductive and oxidative pathway. To our knowledge, there is limited reporting on the application of $\mathrm{Fe}^{0} @ \mathrm{Fe}_{3} \mathrm{O}_{4} \mathrm{NPs}$ in terms of AOPs, especially the heterogeneous Fenton-like reaction system for the rapid degradation of 2,4-D contaminated water.

In this study, a heterogeneous Fenton-like system was constructed with the combination of hydrogen peroxide and $\mathrm{Fe}^{0} @ \mathrm{Fe}_{3} \mathrm{O}_{4}$ NPs and was applied to the oxidative degradation of 2,4-D. Factors such as the initial $\mathrm{pH}$ of the solution, temperature, hydrogen peroxide concentration, and catalyst dosage were investigated to evaluate the effects of different reaction conditions. The degradation pathway of 2,4-D and the possible mechanism in the $\mathrm{Fe}^{0} @ \mathrm{Fe}_{3} \mathrm{O}_{4} / \mathrm{H}_{2} \mathrm{O}_{2}$ system were proposed by testing the changes of ferrous ions/chloride ions and determining the products during the degradation of the target pollutants. The main purpose of this study is to provide a more effective way to achieve the degradation of 2,4-D in the heterogeneous Fenton-like system motivated by the $\mathrm{Fe}^{0} @ \mathrm{Fe}_{3} \mathrm{O}_{4} \mathrm{NPs}$ and hydrogen peroxide, thereby improving the adaptability of this modified catalyst. Meanwhile, it may also contribute to the remediation of other organochlorine pollutants.

\section{Materials and Methods}

\subsection{Chemicals and Reagents}

All chemicals were obtained from commercial sources and used as received: 2,4-D ( $>98.8 \%$ Merck, Darmstadt, Germany), Ferrous sulfate $\left(\mathrm{FeSO}_{4} \cdot 7 \mathrm{H}_{2} \mathrm{O}\right.$, $\left.99.5 \%\right)$, Ferric sulfate $\left(\mathrm{Fe}_{2}\left(\mathrm{SO}_{4}\right)_{3}\right.$, $>99.5 \%)$, sodium borohydride $\left(\mathrm{NaBH}_{4},>99.5 \%\right)$, hydrogen peroxide $\left(\mathrm{H}_{2} \mathrm{O}_{2}, 30 \%\right)$, methanol $(>99.9 \%)$, ethanol (>99.7\%), n-butanol (>99.5\%), and potassium iodide (KI) (>99.0\%). Except 2,4-D, all the above chemicals were analytical grade (AR). The prepared 2,4-D stock solution $(50 \mathrm{mg} / \mathrm{L})$ was stored at $35^{\circ} \mathrm{C}$. 


\subsection{Preparation of $\mathrm{Fe}^{0} @ \mathrm{Fe}_{3} \mathrm{O}_{4}$ Nanoparticles}

The $\mathrm{Fe}_{3} \mathrm{O}_{4} \mathrm{NPs}$ were prepared by the co-precipitation method and are depicted in Equation (1) [20]. Under the atmosphere of $\mathrm{N}_{2}$ injection $(0.1 \mathrm{~L} / \mathrm{min})$, the $\mathrm{Fe}^{2+} / \mathrm{Fe}^{3+}$ solution was prepared ( $4.99 \mathrm{~g}$ $\left.\mathrm{Fe}_{2}\left(\mathrm{SO}_{4}\right)_{3}, 6.95 \mathrm{~g} \mathrm{FeSO}_{4} \cdot 7 \mathrm{H}_{2} \mathrm{O}\right)$ and added drop-wise to the heated $\mathrm{NaOH}$ solution $(0.5 \mathrm{M})$ with electric stirring (150 r/min). When the reaction was completed, the gained $\mathrm{Fe}_{3} \mathrm{O}_{4} \mathrm{NPs}$ were washed twice by ultra-pure water, collected by magnetic separation, and kept by freeze-drying preservation.

$$
\mathrm{Fe}^{2+}+2 \mathrm{Fe}^{3+}+8 \mathrm{OH}^{-} \rightarrow \mathrm{Fe}_{3} \mathrm{O}_{4}+4 \mathrm{H}_{2} \mathrm{O}
$$

With a continuous $\mathrm{N}_{2}$ injection $(0.1 \mathrm{~L} / \mathrm{min}), \mathrm{FeSO}_{4} \cdot 7 \mathrm{H}_{2} \mathrm{O}(0.62 \mathrm{~g})$ was dissolved in $250 \mathrm{~mL}$ of ultra-pure water and mixed with the prepared $\mathrm{Fe}_{3} \mathrm{O}_{4} \mathrm{NPs}(0.5 \mathrm{~g})$, then a drop-wise addition of $250 \mathrm{~mL}$ of $\mathrm{NaBH}_{4}$ solution $(0.018 \mathrm{M})$ into the mixed solution was conducted to realize the reduction of $\mathrm{Fe}^{2+}$ and form the nZVI particles (Equation (2)) [21].

$$
\mathrm{nFe}_{3} \mathrm{O}_{4}-\mathrm{Fe}^{2+}+2 \mathrm{BH}_{4}^{-}+6 \mathrm{H}_{2} \mathrm{O} \rightarrow \mathrm{nFe}_{3} \mathrm{O}_{4}-\mathrm{nZVI}+2 \mathrm{~B}(\mathrm{OH})_{3}+7 \mathrm{H}_{2} \uparrow
$$

The $\mathrm{Fe}^{0} @ \mathrm{Fe}_{3} \mathrm{O}_{4}$ nanoparticles were collected by magnetic separation and washed by ultra-pure water to neutral pH. Finally, the $\mathrm{Fe}^{0} @ \mathrm{Fe}_{3} \mathrm{O}_{4}$ NPs were freeze-dried and preserved under nitrogen protection from oxidation for further use. For this prepared catalyst, the mass ratio of $\mathrm{Fe}_{3} \mathrm{O}_{4}: \mathrm{Fe}^{0}$ was 4:1.

\subsection{Characterization and Analysis Methods}

The particle morphology was investigated by scanning electron microscope (SEM) (Carl-Zeiss Microscopy GmbH, 73447 Oberkochen, Germany), and X-ray photo-electron spectroscopy (XPS) (JPS-9010TR, JEOL, Japan) was applied for qualitative analysis and elemental composition.

High performance liquid chromatography (HPLC Waters 1525) with a reversed-phase C-18 column $(4.6 \times 150 \mathrm{~mm}, 5 \mu \mathrm{m}$ particle diameter) and a UV detector (Waters 2487) was used for the detection of 2,4-D concentration. The mobile phase composition was methanol/water/acetic acid (75:23:2\%, v/v/v), while the flow rate of the mobile phase was settled at $1 \mathrm{~mL} / \mathrm{min}$. The injection volume was $20 \mu \mathrm{L}$, and the analysis was conducted at $\lambda=285 \mathrm{~nm}$ via UV detection. The $\mathrm{pH}$ value was measured using a $\mathrm{pH}$ meter (Thermo star-A $211 \mathrm{pH}$ meter).

Gas chromatography/mass spectrometry (GC-MS, Agilent 7890A/Agilent 5975C) equipped with a HP-5MS column $(30 \mathrm{~m} \times 0.25 \mu \mathrm{m} \times 0.25 \mathrm{~mm})$ was chosen for intermediate products' analysis. High-purity helium (99.99\%) was used as the carrier gas with a flow rate of $1.0 \mathrm{~mL} / \mathrm{min}$, and the split ratio was 5:1. After holding for $1 \mathrm{~min}$, the original GC oven temperature $\left(35^{\circ} \mathrm{C}\right)$ was increased to $300^{\circ} \mathrm{C}$ at a rate of $7.0^{\circ} \mathrm{C} / \mathrm{min}$ and held for $1 \mathrm{~min}$. The injector and detector temperatures were both $280^{\circ} \mathrm{C}$, and the injection volume was $1 \mu \mathrm{L}$.

The 1,10-phenanthroline method was applied to measure the concentration of total dissolved iron and ferrous ion by a UV-Vis spectrophotometer (Agilent Cary 300), while the hydrogen peroxide concentration was determined by the spectrophotometric method $[7,22]$.

Chloride and some short-chain organic acids were measured by ion chromatograph (IC, Dionex ICS-900) with a DS5 conductivity detector and an IonPac AS23 analytical column (Dionex $4 \times 250 \mathrm{~mm}$ ) with an IonPac AG 23 guard column (Dionex $4 \times 50 \mathrm{~mm}$ ). Total organic carbon was tested by the Multi TOC Analyzer (2100, Analytik Jena AG Corporation, Jena, Germany).

\subsection{Batch Experiments}

Batch experiments were conducted to investigate the impacts of different reaction conditions on 2,4-D removal efficiency by $\mathrm{Fe}^{0} @ \mathrm{Fe}_{3} \mathrm{O}_{4}$. A certain amount of $\mathrm{Fe}^{0} @ \mathrm{Fe}_{3} \mathrm{O}_{4}$ particles and $\mathrm{H}_{2} \mathrm{O}_{2}$ were added into $100 \mathrm{~mL}$ serum bottles with a given concentration of 2,4-D solution. The bottles, double sealed with Teflon butyl stopper and an aluminum cover, were placed in a water bath shaker with a rotation 
speed of $175 \mathrm{rpm}$ under a constant temperature and run in triplicate. A powerful magnet was used to separate $\mathrm{Fe}^{0} @ \mathrm{Fe}_{3} \mathrm{O}_{4}$ particles from the solution to have an easier sampling and reduce errors. Aliquots of the samples were taken by a glass syringe at certain time intervals, filtered through $0.22 \mu \mathrm{m}$ filter membranes, and collected into $2 \mathrm{~mL}$ vials containing $10 \mu \mathrm{L}$ of $\mathrm{n}$-butanol $(1 \mathrm{M})$, which was to quench the reaction. To explore the optimum reaction conditions, the temperature, $\mathrm{pH}, \mathrm{Fe}^{0} @ \mathrm{Fe}_{3} \mathrm{O}_{4}$ dosage, and $\mathrm{H}_{2} \mathrm{O}_{2}$ concentration were tested, with one parameter changing while the others remained unchanged. The initial temperature was set for $20^{\circ} \mathrm{C}, 30^{\circ} \mathrm{C}, 35^{\circ} \mathrm{C}, 40^{\circ} \mathrm{C}$, and $45^{\circ} \mathrm{C}$, while the initial pH ranged from 3.0 to 8.0. Different $\mathrm{Fe}^{0} @ \mathrm{Fe}_{3} \mathrm{O}_{4}$ dosages of $0.1 \mathrm{~g} / \mathrm{L}, 0.3 \mathrm{~g} / \mathrm{L}, 0.5 \mathrm{~g} / \mathrm{L}, 0.8 \mathrm{~g} / \mathrm{L}$, and $1.0 \mathrm{~g} / \mathrm{L}$ were investigated, and the $\mathrm{H}_{2} \mathrm{O}_{2}$ concentration was studied from $0.5 \mathrm{mg} / \mathrm{L}$ to $5.0 \mathrm{mg} / \mathrm{L}$. Under the optimum reaction conditions, contrast experiments of the 2,4-D removal efficiency in different reaction systems $\left(\mathrm{Fe}^{0} @ \mathrm{Fe}_{3} \mathrm{O}_{4}, \mathrm{nZVI}\right.$ and $\mathrm{Fe}_{3} \mathrm{O}_{4}$ particles with or without hydrogen peroxide) were conducted. $\mathrm{EtOH}$ and TBA were employed as radical scavengers to distinguish the degradation contributions of the radicals formed in the reaction system.

\section{Results and Discussion}

\subsection{Characterization of $\mathrm{Fe}^{0} @ \mathrm{Fe}_{3} \mathrm{O}_{4} \mathrm{NPS}$}

As shown in Figure 1b, $\mathrm{Fe}^{0} @ \mathrm{Fe}_{3} \mathrm{O}_{4}$ NPs have a chainlike distribution because of the magnetic dipole interaction and their nano-size. The nanoparticle sizes were in the range of 30-200 nm. According to the results of our previous studies [23], these spherically shaped particles presented in Figure 1d had a structure consisting of nZVI attaching to the surface of $\mathrm{Fe}_{3} \mathrm{O}_{4}$ particles. Compared with pure nZVI in Figure $1 \mathrm{a}$ and some relevant studies [24,25], the prepared complex composite had a better dispersity, which might be owed to the introduction of $\mathrm{Fe}_{3} \mathrm{O}_{4}$. As the supporter, magnetite could not only help to optimize the agglomeration of nZVI, but also accelerate electrons' transfer from nZVI to targeted pollutants for the formation of numerous $\mathrm{Fe}^{0}-\mathrm{Fe}_{3} \mathrm{O}_{4}$ batteries. It is demonstrated in Figure $1 \mathrm{c}$ that, after 90 min of reaction, particle aggregation occurred with the increasing of particle sizes, owing to the consumption of both $\mathrm{Fe}^{0}$ and $\mathrm{Fe}_{3} \mathrm{O}_{4}$, which would change the morphology and components of the prepared catalyst.

The XPS spectra in Figure 2a revealed that the original $\mathrm{Fe}^{0} @ \mathrm{Fe}_{3} \mathrm{O}_{4} \mathrm{NPs}$ consisted of elements Fe, $\mathrm{O}$, and $\mathrm{C}$. The $\mathrm{C} 1 \mathrm{~s}$ peak at $284.8 \mathrm{eV}$ could be attributed to the adventitious carbon from the sample preparation and analysis.

The freshly gained catalyst had two peaks at $710.4 \mathrm{eV}$ and $724.0 \mathrm{eV}$, which were assigned to $\mathrm{Fe}_{3} \mathrm{O}_{4}$ $(\mathrm{Fe}(\mathrm{II}) / \mathrm{Fe}(\mathrm{III}))$, whose positions were consistent with the related literature values of 710.6 and $724.1 \mathrm{eV}$, respectively. The binding energies of Fe 2p3/2 and Fe 2p1/2 detected at $712.2 \mathrm{eV}$ and $725.9 \mathrm{eV}$ were similar to those of $\mathrm{Fe}_{2} \mathrm{O}_{3}(\mathrm{Fe}(\mathrm{III}))\left(\mathrm{Fe} 2 \mathrm{p}_{3 / 2}, 711.0 \mathrm{eV} ; \mathrm{Fe} 2 \mathrm{p}_{1 / 2}, 726.4 \mathrm{eV}\right)$. Meanwhile, it was reported that the $\mathrm{Fe} 2 \mathrm{p} 3 / 2$ peak of $\mathrm{Fe}_{2} \mathrm{O}_{3}$ has associated satellite peaks, which are located approximately $8 \mathrm{eV}$ higher than the main Fe 2p3/2 peak [26]. It is the fact to which the peak with lower binding energy of $719.4 \mathrm{eV}$ could be ascribed. The existence of $\mathrm{Fe}_{2} \mathrm{O}_{3}$ in the originally prepared sample might be due to the unavoidable oxidation of superficial nZVI during preparation and storage.

The composite comprised of small amounts of nZVI $(\mathrm{Fe}(0))$ showed a peak at a low binding energy of $707.4 \mathrm{eV}$, which was attributed to $\mathrm{Fe}_{2} \mathrm{p}_{3 / 2}$ in $\mathrm{Fe}^{0}(706.7 \mathrm{eV})$. Moreover, the low-intensity peaks of nZVI might be ascribed to the thickness of the iron-oxide shell because XPS can only detect the photoelectrons from within $10 \mathrm{~nm}$ of the outer surface of a target.

With increasing reaction time, peaks of $\mathrm{Fe}(0)$ disappeared for the consumption of $\mathrm{nZVI}$ and the deposition of iron oxides, while peaks of $\mathrm{Fe}_{2} \mathrm{O}_{3}$ and $\mathrm{Fe}_{3} \mathrm{O}_{4}$ changed in different degrees. The formation of more iron oxide would indeed lead to the increase of $\mathrm{Fe}_{2} \mathrm{O}_{3}$, but similar to $\mathrm{Fe}_{3} \mathrm{O}_{4}$, those newly formed ones could also react with hydrogen peroxide to help with pollutant degradation, causing the decrease of $\mathrm{Fe}_{2} \mathrm{O}_{3}$ and $\mathrm{Fe}_{3} \mathrm{O}_{4}$ in the composite. 
As time passed, the peak of lepidocrocite $(\gamma-\mathrm{FeOOH})$ was detected at $713.3 \mathrm{eV}$ in the sample after the reaction. Sampling of the reaction solution by syringe inevitably led to air egress, and the produced $\mathrm{Fe}^{2+}$ would react with oxygen and water, which might lead to the production of FeOOH (Equation (3)).

$$
4 \mathrm{Fe}^{2+}+\mathrm{O}_{2}+6 \mathrm{H}_{2} \mathrm{O} \rightarrow 4 \mathrm{FeOOH}+8 \mathrm{H}^{+}
$$
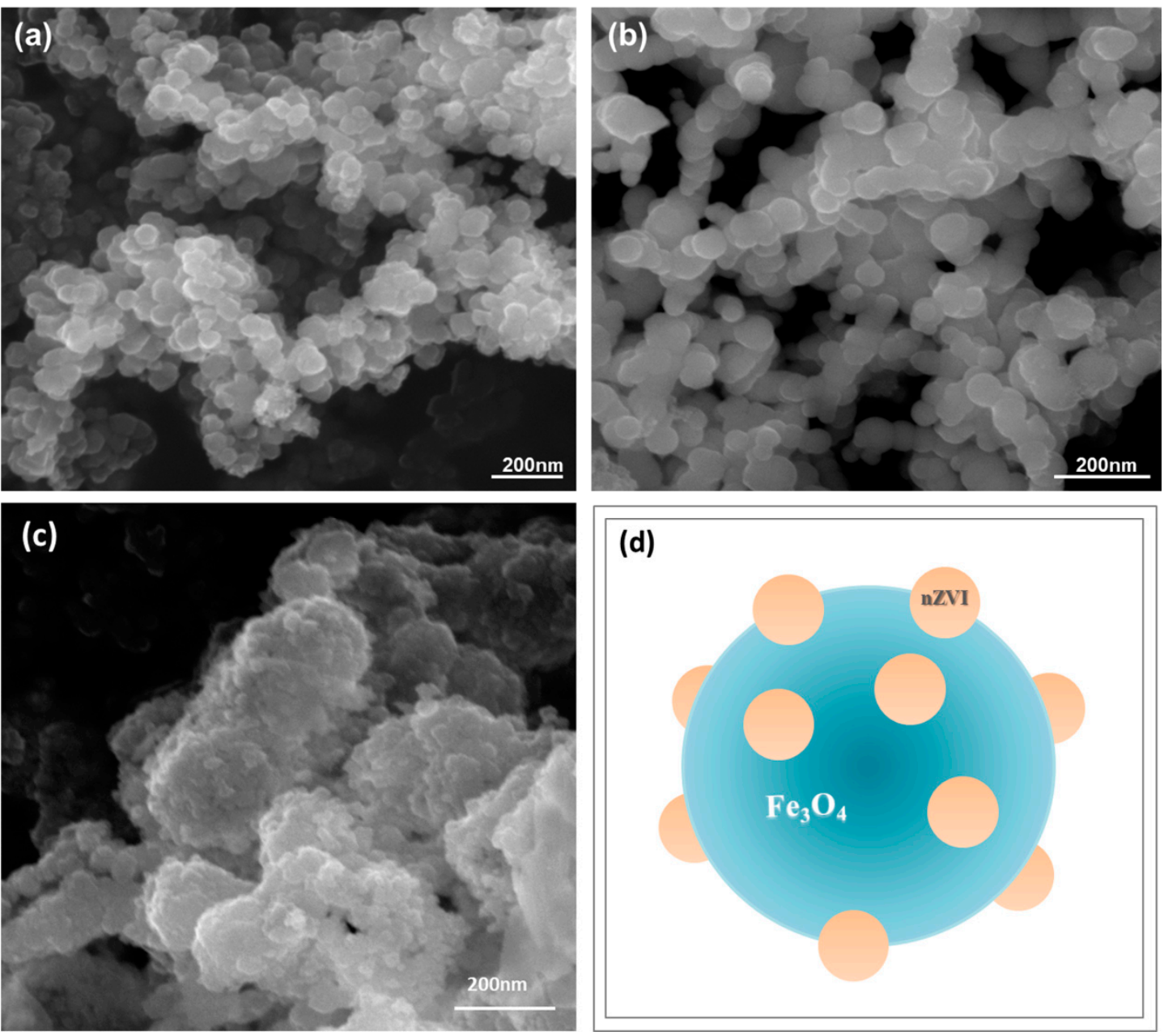

Figure 1. SEM images of (a) nano zero-valent iron (nZVI), (b) the original $\mathrm{Fe}^{0} @ \mathrm{Fe}_{3} \mathrm{O}_{4} \mathrm{NPs}$, and (c) the $\mathrm{Fe}^{0} @ \mathrm{Fe}_{3} \mathrm{O}_{4}$ NPs after reaction, and (d) the conceptual model of the $\mathrm{Fe}^{0} @ \mathrm{Fe}_{3} \mathrm{O}_{4} \mathrm{NPs}$.
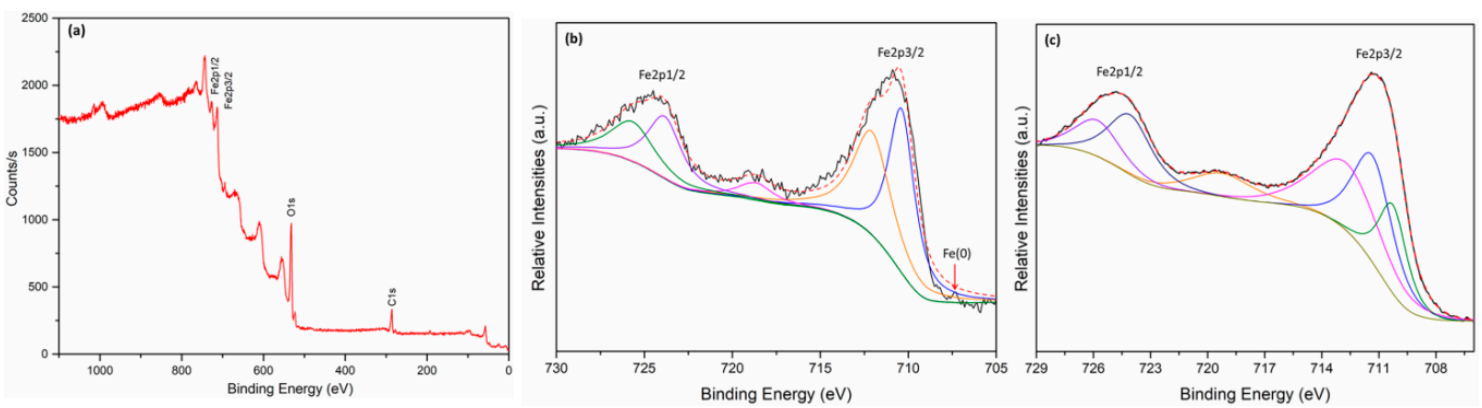

Figure 2. (a) Full spectrum X-ray photoelectron patterns of the $\mathrm{Fe}^{0} @ \mathrm{Fe}_{3} \mathrm{O}_{4} \mathrm{NPs}$; narrow region X-ray photoelectron patterns of $\mathrm{Fe} 2 \mathrm{p}$ for the $\mathrm{Fe}^{0} @ \mathrm{Fe}_{3} \mathrm{O}_{4} \mathrm{NPs}$ : (b) original (c) after reaction. 


\subsection{Batch Experiments}

\subsubsection{Effect of Initial $\mathrm{pH}$}

The $\mathrm{pH}$ value is an important factor that can have significant effects on the degradation of organic pollutants, as well as the form of iron and hydrogen peroxide in Fenton and Fenton-like systems. Removal of 2,4-D under different $\mathrm{pH}$ values varying from 3.0 to 8.0 were investigated, and the results were shown in Figure 3. Under the conditions of $\mathrm{pH}=3.0,4.5$, and 5.0, no 2,4-D was left in the solution after $90 \mathrm{~min}$, but when it continued to increase to 5.5 and above, the pollutant removal efficiency decreased rapidly; the final reduction of $2,4-\mathrm{D}$ was only $11 \%$ at $\mathrm{pH}=8.0$.

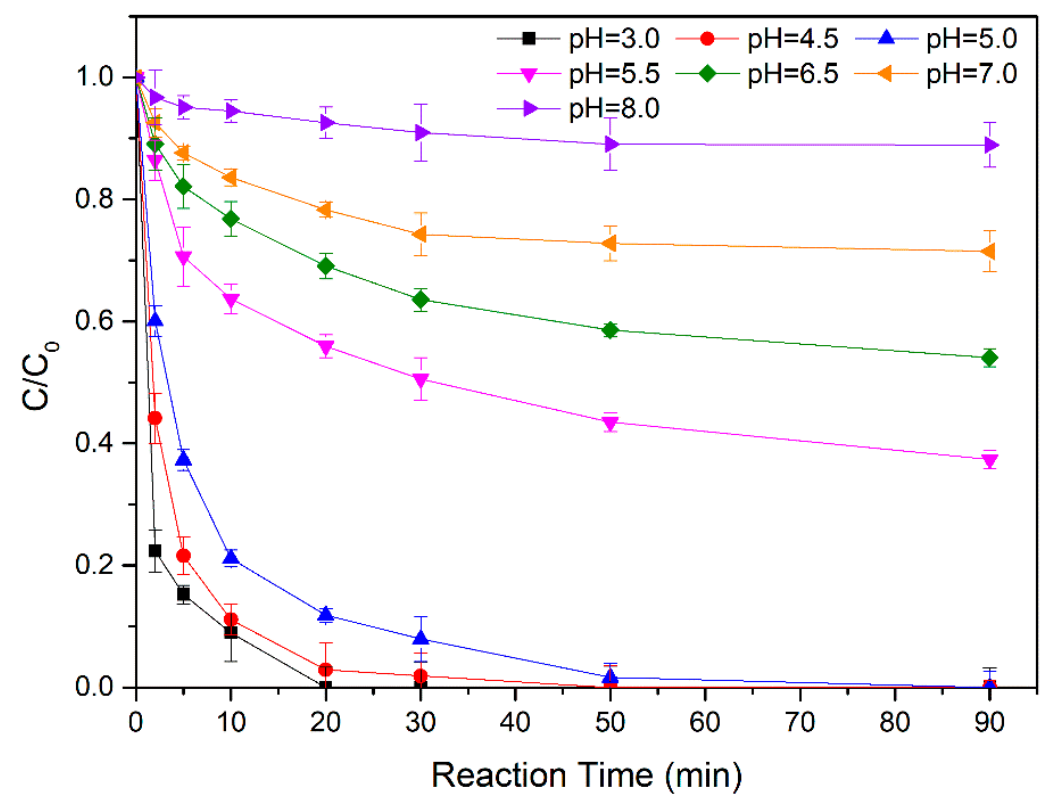

Figure 3. Effect of $\mathrm{pH}$ on 2,4-dichlorophenoxyacetic acid (2,4-D) degradation $\left([2,4-\mathrm{D}]_{0}=5.0 \mathrm{mg} / \mathrm{L}\right.$, $\left.\left[\mathrm{Fe}^{0} @ \mathrm{Fe}_{3} \mathrm{O}_{4}\right]_{0}=0.5 \mathrm{~g} / \mathrm{L}, \mathrm{H}_{2} \mathrm{O}_{2}=1 \mathrm{mM}, \mathrm{T}=30^{\circ} \mathrm{C}\right)$.

Decreasing $\mathrm{pH}$ can gradually accelerate the removal of target pollutants, while a higher $\mathrm{pH}$ value may lead to the formation of iron oxyhydroxide and the precipitation of iron hydroxide, which will reduce the activity of the Fenton reagent. Under alkaline conditions, the reduction of ferrous/ferric ions will in turn restrict the generation of hydroxyl radicals; the oxidation potential of the hydroxyl radicals will also decrease with the increasing $\mathrm{pH}$ value. In addition, a higher $\mathrm{pH}$ will accelerate the decomposition of hydrogen peroxide into oxygen and water. All the above reasons are unfavorable for the efficient degradation of 2,4-D.

The optimal $\mathrm{pH}$ for the traditional Fenton process was found to be around 3 as a $\mathrm{pH}$ above 3 could significantly reduce the degradation efficiency of the target pollutants [27]. Meanwhile, if the $\mathrm{pH}$ value of the solution is too low, there will be a large amount of $\left[\mathrm{Fe}\left(\mathrm{H}_{2} \mathrm{O}\right)_{6}\right]^{2+}$ existing in the system, which has more difficulty reacting with hydrogen peroxide when compared with the other iron substances [28]. At the same time, the reaction rate between hydrogen ions and hydroxyl radicals will also be greatly accelerated (Equation (4)). In addition, a high concentration of hydrogen ions will cause the dissolution of peroxide to form the hydronium ion, which is much more stable and will make it very difficult for hydrogen peroxide to react with $\mathrm{Fe}^{2+} / \mathrm{Fe}^{3+}$ and then influence the release of free radicals. Therefore, the appropriate range of $\mathrm{pH}$ is an important prerequisite to ensure efficient degradation of pollutants since the Fenton reaction may not proceed effectively when the solution $\mathrm{pH}$ is too high or too low.

$$
\mathrm{OH}+\mathrm{H}^{+}+\mathrm{e}^{-} \rightarrow \mathrm{H}_{2} \mathrm{O}
$$


However, in the range of $\mathrm{pH}=3.0-5.5$, removal of 2,4- $\mathrm{D}$ was maintained above $80 \%$, and even under the condition of $\mathrm{pH}=6.5$, still nearly $50 \%$ of 2,4-D could be removed in $90 \mathrm{~min}$. Compared with other studies $[29,30]$, the inhibition along with the change of $\mathrm{pH}$ were not that obvious, indicating that the $\mathrm{Fe}^{0} @ \mathrm{Fe}_{3} \mathrm{O}_{4} / \mathrm{H}_{2} \mathrm{O}_{2}$ system in this study could adapt to a wider $\mathrm{pH}$ range.

Generally speaking, the acidic condition was more favorable to the reaction; but there are still research works pointing out that the degradation efficiency of pollutants was higher under neutral or even weakly alkaline conditions. For a different catalyst, the same $\mathrm{pH}$ value might lead to different results due to differences in the mechanism of their reaction. The effects of catalysts by releasing metal ions was greatly affected by $\mathrm{pH}$; the increase of $\mathrm{pH}$ would slow down or even stop the dissolution of metal ions and make it inactivated through hydrolysis and precipitation; but those catalysts participating in the reaction through the active sites on their surface were more adaptable to $\mathrm{pH}$ change. Anyway, regardless of any catalytic system, the reaction $\mathrm{pH}$ needs to be controlled within the appropriate range. Considering the high efficiency of the $\mathrm{Fe}^{0} @ \mathrm{Fe}_{3} \mathrm{O}_{4} / \mathrm{H}_{2} \mathrm{O}_{2}$ system without $\mathrm{pH}$ adjusting, the follow-up experiments were conducted with no adjustment of $\mathrm{pH}(\mathrm{pH}=5.0 \pm 0.2)$.

\subsubsection{Effect of Hydrogen Peroxide Concentration}

Hydrogen peroxide is the primary source of hydroxyl radicals and plays a vital role in the Fenton-like catalytic oxidation process. For different systems, its dosage changes according to the types and properties of the target pollutants and the catalyst. Experiments with different ranges of hydrogen peroxide were undertaken to determine the optimal concentration for $\mathrm{Fe}^{0} @ \mathrm{Fe}_{3} \mathrm{O}_{4}$. As shown in Figure 4, without the addition of the catalyst, hydrogen peroxide alone could hardly achieve 2,4-D degradation. Little hydrogen peroxide would result in insufficient release of the hydroxyl radical, which directly affects the degradation efficiency of organic contaminants, but in this study, a small amount of hydrogen peroxide could achieve a good removal of 2,4-D. At a concentration of $0.5 \mathrm{mM}$, eighty-two percent of 2,4-D was removed in $90 \mathrm{~min}$; when the concentration of hydrogen peroxide increased to $1 \mathrm{mM}$, no 2,4-D remained in the solution at the end of the reaction. Further increasing the concentration to $2 \mathrm{mM}$ and $3 \mathrm{mM}$ could accelerate the removal of 2,4-D and shorten the reaction time to $50 \mathrm{~min}$, but it is worth noting that although the time consumption was reduced, at the beginning of the reaction (especially within the first $10 \mathrm{~min}$ ), for the condition of $2 \mathrm{mM}$ and $3 \mathrm{mM}$, the decline of 2,4-D was slower than that of $1 \mathrm{mM}$, then gradually accelerated with time and came to an early end.

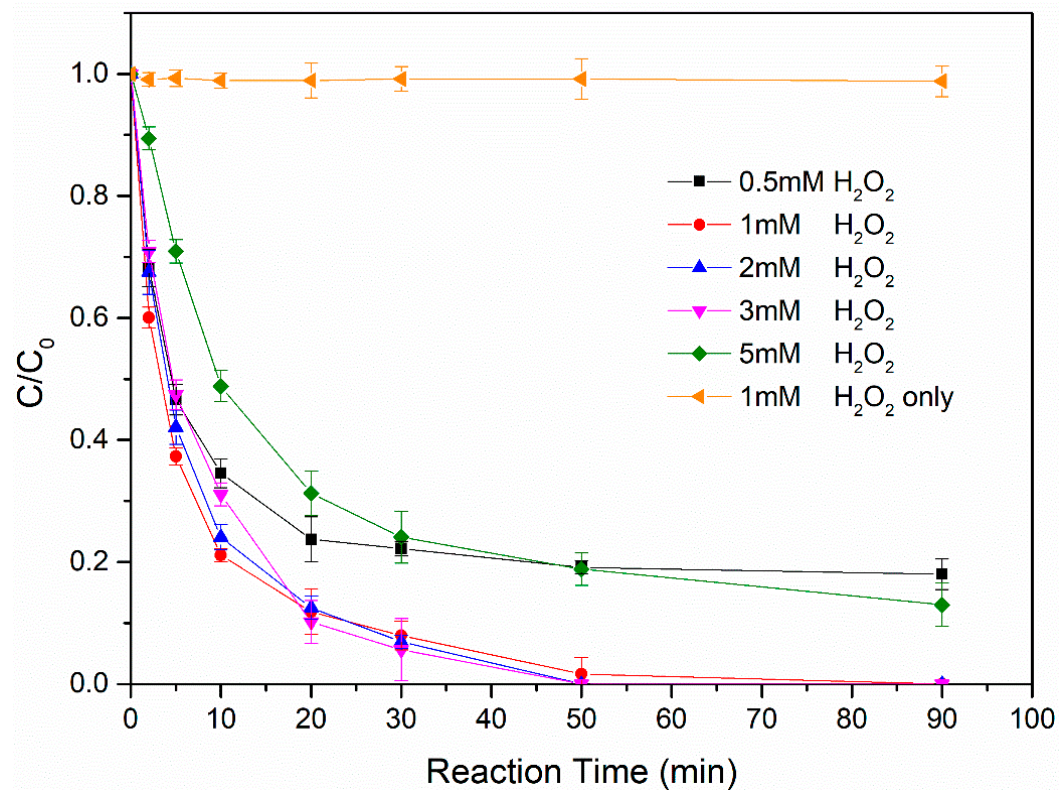

Figure 4. Effect of $\mathrm{H}_{2} \mathrm{O}_{2}$ concentration on 2,4-D degradation ([2,4-D $]_{0}=5.0 \mathrm{mg} / \mathrm{L}$, $\left[\mathrm{Fe}^{0} @ \mathrm{Fe}_{3} \mathrm{O}_{4}\right]_{0}=0.5 \mathrm{~g} / \mathrm{L}$, $\left.\mathrm{pH}=5.0 \pm 0.2, \mathrm{~T}=30^{\circ} \mathrm{C}\right)$. 
The addition of too much hydrogen peroxide would cause a sharp increase of its concentration in solution; part of the hydrogen peroxide quickly decomposed into water and oxygen, while some of it could react with the generated free radicals [31,32]. As a result, the quantity of free radicals was reduced, and in turn, the degradation of 2,4-D was inhibited. When this excessive part of hydrogen peroxide was depleted, more free radicals could be released so that the removal rate of the pollutants increased.

However, when the dosage of hydrogen peroxide continued to increase to $5 \mathrm{mM}$, both the reaction rate and the final removal efficiency deteriorated accordingly. After $90 \mathrm{~min}$, twelve percent of the contaminants were left in the solution. This may be due to the fact that when there was too much hydrogen peroxide existing in the solution, excess $\mathrm{H}_{2} \mathrm{O}_{2}$ would quickly eliminate the generated hydroxyl radicals through the following reactions (Equations (5) and (6)) and convert them to less active $\mathrm{HO}_{2} \cdot$ or $\mathrm{O}_{2}^{-} \cdot$ and greatly influence the treatment of 2,4-D.

In practical applications, excessive hydrogen peroxide will increase the operating cost and the unconsumed $\mathrm{H}_{2} \mathrm{O}_{2}$ will interfere with the Chemical Oxygen Demand (COD) measurement [33]. Besides, since Fenton/Fenton-like processes can be used as a pretreatment and are usually combined with other processes, the biotoxicity of hydrogen peroxide will significantly reduce the degradation efficiency of pollutants in some Fenton-biological combined oxidation treatment process.

$$
\begin{gathered}
\mathrm{H}_{2} \mathrm{O}_{2}+\mathrm{OH} \rightarrow \mathrm{H}_{2} \mathrm{O}+\mathrm{HO}_{2} \\
\mathrm{HO}_{2} \leftrightarrow \mathrm{O}_{2}^{-}+\mathrm{H}^{+}
\end{gathered}
$$

\subsubsection{Effects of Temperature}

The effects of temperature on the oxidative degradation of 2,4-D in the $\mathrm{Fe}^{0} @ \mathrm{Fe}_{3} \mathrm{O}_{4}$ heterogeneous Fenton system were investigated under $20^{\circ} \mathrm{C}, 30^{\circ} \mathrm{C}, 35^{\circ} \mathrm{C}, 40^{\circ} \mathrm{C}$, and $45^{\circ} \mathrm{C}$. It can be seen from Figure 5 a that in the range of $20{ }^{\circ} \mathrm{C}$ to $45^{\circ} \mathrm{C}$, as temperature rises, the degradation rate of 2,4-D increases continuously, while the reaction time consumed for the complete removal of target pollutant is gradually shortened; the reaction rate constant $\mathrm{k}_{\mathrm{a}}$ increased from $4.58 \times 10^{-2} \mathrm{~min}^{-1}$ to $3.65 \times 10^{-1} \mathrm{~min}^{-1}$, respectively. At the maximum temperature of $45^{\circ} \mathrm{C}$, it only took $30 \mathrm{~min}$ for all $5.0 \mathrm{mg} / \mathrm{L} \mathrm{2,4-D}$ in the solution to disappear. The rise of temperature could not only contribute to the corrosion of zero-valent iron and the generation of hydroxyl radicals, but also accelerate the movement of reactant molecules, increase the collision probability of 2,4-D molecules with free radicals, then enhance removal efficiency.
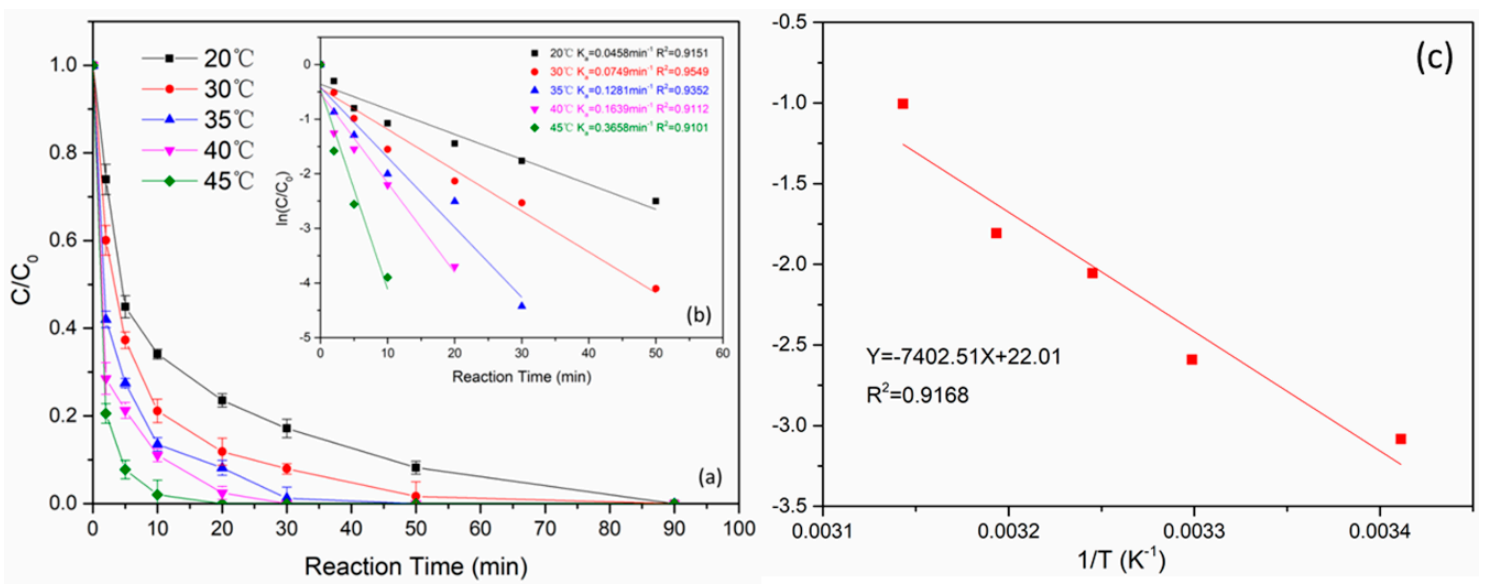

Figure 5. (a) Effect of temperature on 2,4-D degradation. (b) Dynamic simulation of 2,4-D degradation under different temperatures. (c) Fitting curve of $\ln (\mathrm{K}) / \mathrm{T}\left([2,4-\mathrm{D}]_{0}=5.0 \mathrm{mg} / \mathrm{L},\left[\mathrm{Fe}^{0} @ \mathrm{Fe}_{3} \mathrm{O}_{4}\right]_{0}=0.5 \mathrm{~g} / \mathrm{L}\right.$, $\mathrm{H}_{2} \mathrm{O}_{2}=1 \mathrm{mM}, \mathrm{pH}=5.0 \pm 0.2$ ). 
The thermodynamic analysis was conducted for a further study of the temperature effects on the oxidative degradation process of 2,4-D. According to the Arrhenius equation, the functional relationship between temperature and rate constants could be described as follows [34,35]:

$$
\mathrm{k}=\mathrm{A} \times \mathrm{e}^{-\frac{\mathrm{E}_{\mathrm{a}}}{\mathrm{RT}}}
$$

where $\mathrm{k}$ is the measured pseudo-first-order rate constant, $\mathrm{E}_{\mathrm{a}}$ is the activation energy, $\mathrm{A}$ is a frequency factor, $R$ is the universal gas constant $\left(8.314 \mathrm{Jmol}^{-1} \mathrm{~K}^{-1}\right)$, and $\mathrm{T}$ is the temperature $(\mathrm{K})$. Integrating Equation (7) resulted in:

$$
\operatorname{lnk}=-\frac{E_{a}}{R} \times \frac{1}{T}+\ln \mathrm{A}
$$

Therefore, defining the $k_{a}$ obtained from Figure $5 \mathrm{~b}$ as $k$, a plot of lnk versus $1 / \mathrm{T}$ resulted in a linear relationship with the slope and the intercept equal to $-\mathrm{E}_{\mathrm{a}} / \mathrm{R}$ and $\ln \mathrm{A}$ as illustrated in Figure $5 \mathrm{c}$. In this study, we investigated the activation energy for the removal of 2,4- $\mathrm{D}$ by $\mathrm{Fe}^{0} @ \mathrm{Fe}_{3} \mathrm{O}_{4} / \mathrm{H}_{2} \mathrm{O}_{2}$ at different temperatures ranging from $20^{\circ} \mathrm{C}$ to $45^{\circ} \mathrm{C}$, and the value was calculated to be $61.55 \mathrm{KJ} / \mathrm{mol}$, which was greater than that of diffusion-controlled reactions $(\sim 29 \mathrm{~kJ} / \mathrm{mol})$. It could be inferred that this process was a surface-mediated reaction; the rate-limiting step of 2,4-D degradation was not diffusion, but surface-chemical reaction [36]. Since the optimal temperature of the Fenton-like process is usually controlled at about $25-30{ }^{\circ} \mathrm{C}$, excessive temperature will accelerate the decomposition of hydrogen peroxide into water and oxygen, thereby reducing removal efficiency. Considering the cost and operation convenience, thirty degrees Celsius was chosen as the experimental temperature in this study.

\subsubsection{Effect of $\mathrm{Fe}^{0} @ \mathrm{Fe}_{3} \mathrm{O}_{4}$ Dosage}

Without adding hydrogen peroxide, about $20 \%$ of 2,4-D could be removed in $90 \mathrm{~min}$, which was due to the adsorption and the reductive degradation by $\mathrm{Fe}^{0} @ \mathrm{Fe}_{3} \mathrm{O}_{4}$ particles. Dechlorination was the main approach for 2,4-D reducing, when there was no hydrogen peroxide added in solution, but the removal rate of pollutants by $\mathrm{Fe}^{0} @ \mathrm{Fe}_{3} \mathrm{O}_{4}$ was much slower than that of the Fenton system. The results in Figure 6 show that when the concentration of hydrogen peroxide was $1 \mathrm{mM}$, the removal rate of 2,4-D gradually increased with the increase of catalyst dosage, and even a small amount of $\mathrm{Fe}^{0} @ \mathrm{Fe}_{3} \mathrm{O}_{4}$ nanoparticles could achieve a good removal efficiency. Under the condition of $0.1 \mathrm{~g} / \mathrm{L}$ and $0.3 \mathrm{~g} / \mathrm{L}$, the 2,4-D removal efficiencies were greater than $70 \%$, but there were still contaminants remaining in the solution at the end ( $29 \%$ and $16 \%$, respectively). nZVI in the catalytic particles was the main source of $\mathrm{Fe}^{2+}$ in this reaction system, and insufficient ferrous ion would lead to less production of free radicals, which directly affected the degradation of 2,4-D. In addition, a proper dosage of $\mathrm{Fe}^{0} @ \mathrm{Fe}_{3} \mathrm{O}_{4}$ was the guarantee of sufficient active sites for reaction. 

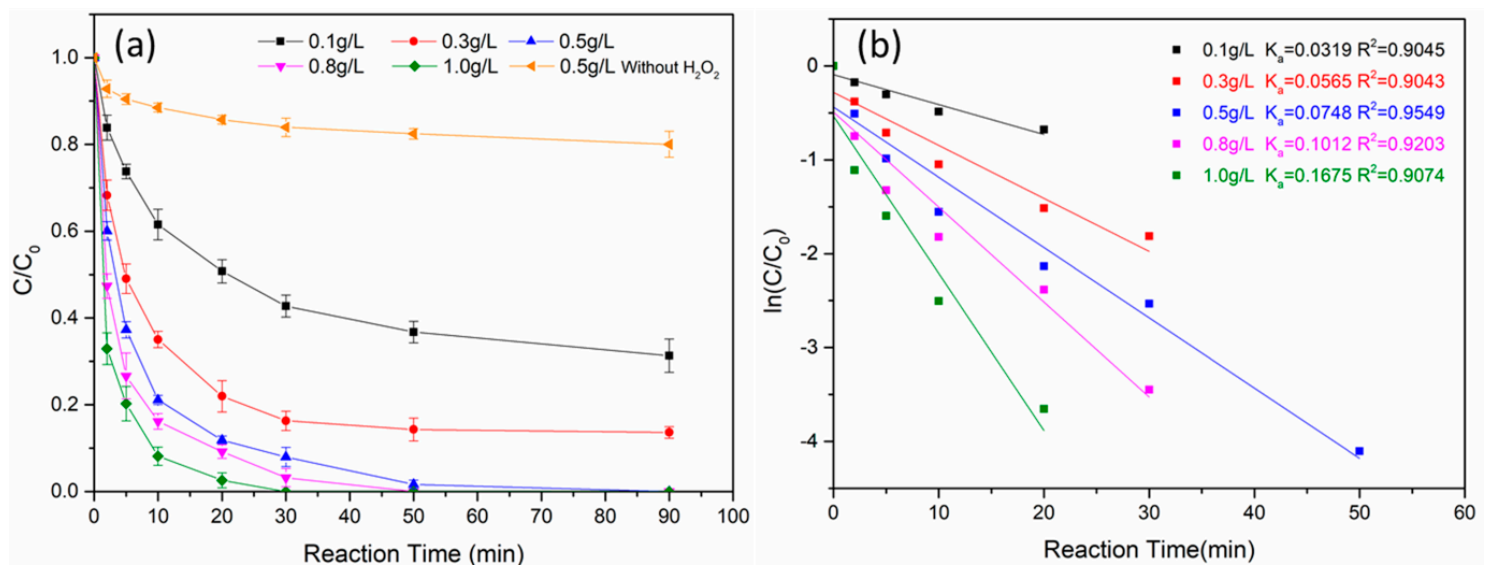

Figure 6. (a) Effect of catalyst dosage on 2,4-D degradation. (b) Dynamic simulation of 2,4-D degradation under different catalyst dosages $\left([2,4-\mathrm{D}]_{0}=5.0 \mathrm{mg} / \mathrm{L}, \mathrm{H}_{2} \mathrm{O}_{2}=1 \mathrm{mM}, \mathrm{pH}=5.0 \pm 0.2, \mathrm{~T}=30^{\circ} \mathrm{C}\right)$.

When the dosage of catalyst continuously increased to $0.5 \mathrm{~g} / \mathrm{L}$ and above, the pollutants could be completely removed, and the required reaction time was gradually shortened. By calculating the reaction rate constant, it could be seen that as the dosage increased from $0.1 \mathrm{~g} / \mathrm{L}$ to $0.5 \mathrm{~g} / \mathrm{L}, \mathrm{K}_{\mathrm{a}}$ increased by $4.29 \times 10^{-2} \mathrm{~min}^{-1}$, while the increase from $0.5 \mathrm{~g} / \mathrm{L}$ to $0.8 \mathrm{~g} / \mathrm{L}$ and $1.0 \mathrm{~g} / \mathrm{L}$ led to $\mathrm{K}_{\mathrm{a}}$ changes of $2.64 \times 10^{-2} \mathrm{~min}^{-1}$ and $6.53 \times 10^{-2} \mathrm{~min}^{-1}$, respectively. It was inferred that, when the dosage of $\mathrm{Fe}^{0} @ \mathrm{Fe}_{3} \mathrm{O}_{4}$ exceeded $0.5 \mathrm{~g} / \mathrm{L}$, the increasing of the reaction rate would gradually slow down. Within a proper range, increasing the amount of catalyst could accelerate the removal of pollutants, but a large amount of $\mathrm{Fe}^{0} @ \mathrm{Fe}_{3} \mathrm{O}_{4}$ might cause over release of $\mathrm{Fe}^{2+} / \mathrm{Fe}^{3+}$ to react with hydroxyl radicals, leading to the consumption of active ingredients (Equations (9) and (10)) [37]. At the same time, excessive dosing would cause the waste of catalysts and increase the operating costs in practical applications.

$$
\begin{gathered}
\mathrm{Fe}^{2+}+\mathrm{OH} \rightarrow \mathrm{Fe}^{3+}+\mathrm{OH}^{-} \\
\mathrm{Fe}^{3+}+\mathrm{H}_{2} \mathrm{O}_{2} \rightarrow \mathrm{FeOOH}^{2+}+\mathrm{H}^{+}
\end{gathered}
$$

\subsection{Comparison between Different Catalysts on the Degradation of 2,4-D}

To investigate the role of each component in the $\mathrm{Fe}^{0} @ \mathrm{Fe}_{3} \mathrm{O}_{4} / \mathrm{H}_{2} \mathrm{O}_{2}$ heterogeneous Fenton system and have a better understanding of its promotion on 2,4-D removal, the performances of different systems were compared. From high to low, the removal efficiency of 2,4-D in different reaction systems was $\mathrm{Fe}^{0} @ \mathrm{Fe}_{3} \mathrm{O}_{4} / \mathrm{H}_{2} \mathrm{O}_{2}>\mathrm{nZVI} / \mathrm{H}_{2} \mathrm{O}_{2}>\mathrm{Fe}_{3} \mathrm{O}_{4} / \mathrm{H}_{2} \mathrm{O}_{2}>\mathrm{Fe}^{0} @ \mathrm{Fe}_{3} \mathrm{O}_{4}>\mathrm{H}_{2} \mathrm{O}_{2}$. As shown in Figure 7, one-hundred percent of 2,4-D could be removed by the combination of $\mathrm{Fe}^{0} @ \mathrm{Fe}_{3} \mathrm{O}_{4}$ and $\mathrm{H}_{2} \mathrm{O}_{2}$ within 90min. Without the catalysis of $\mathrm{Fe}^{0} @ \mathrm{Fe}_{3} \mathrm{O}_{4}$, few hydroxyl radicals could be generated from the natural decomposition of hydrogen peroxide; simply adding hydrogen peroxide almost had no ability to degrade the pollutants. A shortage of free radicals led to the poor degradation effect of 2,4-D in the $\mathrm{H}_{2} \mathrm{O}_{2}$-only system. The $\mathrm{Fe}_{3} \mathrm{O}_{4} / \mathrm{H}_{2} \mathrm{O}_{2}$ system achieved a removal efficiency of $52.8 \%$ in 90 min, and without the addition of hydrogen peroxide, $\mathrm{Fe}^{0} @ \mathrm{Fe}_{3} \mathrm{O}_{4}$ itself reduced about $20 \%$ of 2,4-D through reduction and adsorption. 


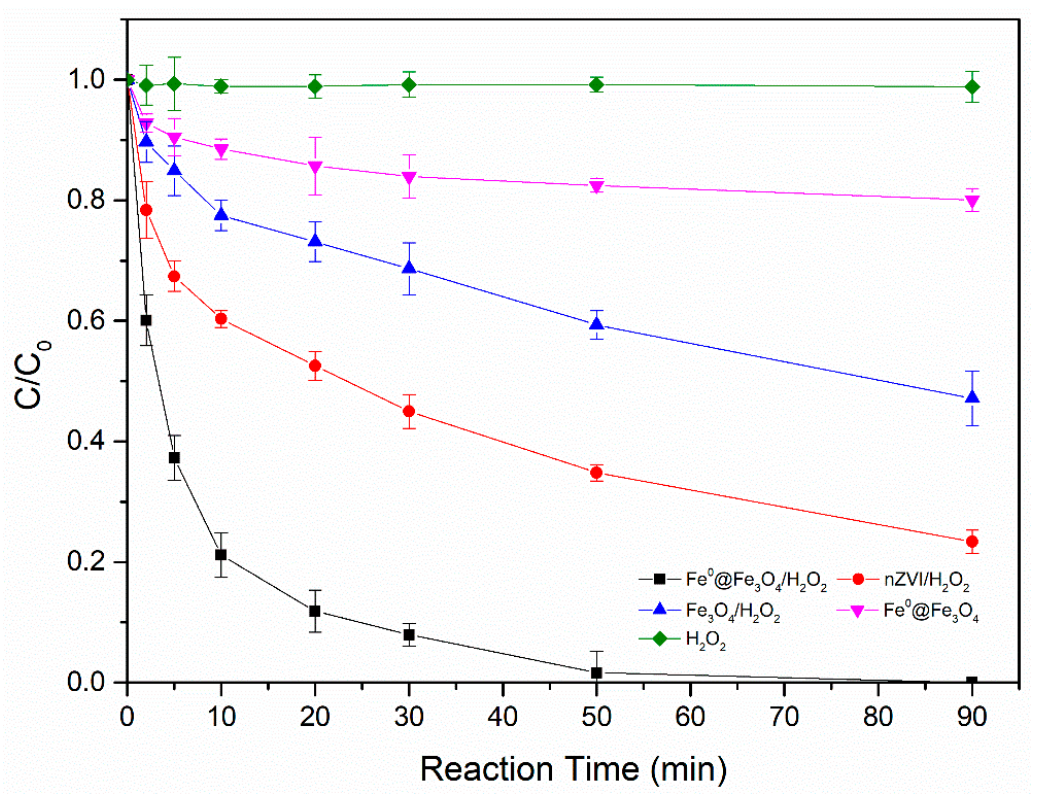

Figure 7. Comparison between different catalysts for the degradation of $2,4-\mathrm{D}\left([2,4-\mathrm{D}]_{0}=5.0 \mathrm{mg} / \mathrm{L}\right.$, $[\text { catalyst }]_{0}=0.5 \mathrm{~g} / \mathrm{L}, \mathrm{H}_{2} \mathrm{O}_{2}=1 \mathrm{mM}, \mathrm{pH}=5.0 \pm 0.2, \mathrm{~T}=30^{\circ} \mathrm{C}$ ).

Although the reductive ability of the nZVI $/ \mathrm{H}_{2} \mathrm{O}_{2}$ system was not as good as that of the $\mathrm{Fe}^{0} @ \mathrm{Fe}_{3} \mathrm{O}_{4} / \mathrm{H}_{2} \mathrm{O}_{2}$ system, the removal of 2,4-D still reached 76.7\% in the same duration, and there was still a trend for further reduction. In this system, the degradation of 2,4-D was mainly attributed to hydroxyl radicals released from the reaction of hydrogen peroxide and ferrous ions produced by the oxidation of nZVI. However, as mentioned above, pure nZVI particles were prone to agglomeration, and that would in turn reduce their reactivity. On the one hand, the introduction of $\mathrm{Fe}_{3} \mathrm{O}_{4}$ as a supporter could avoid the agglomeration of nZVI and increase the specific surface area of catalyst particles. On the other hand, as an active substance, $\mathrm{Fe}_{3} \mathrm{O}_{4}$ itself would participate in the Fenton reaction by releasing structural $\mathrm{Fe}^{2+} / \mathrm{Fe}^{3+}$, increasing the amount of free radicals, and then, improving the degradation effect. Nevertheless, because of the slow release rate of iron ions from the internal structure, its contribution to improving the degradation efficiency of target pollutants was relatively limited. $\mathrm{Fe}^{0} @ \mathrm{Fe}_{3} \mathrm{O}_{4}$ could reduce the concentration of 2,4-D through reductive dechlorination. However, as a highly chlorinated compound, the complex structure of 2,4-D made it more difficult to be degraded, and its reduction process would be much slower.

In summary, the high speed removal of 2,4-D in the $\mathrm{Fe}^{0} @ \mathrm{Fe}_{3} \mathrm{O}_{4} / \mathrm{H}_{2} \mathrm{O}_{2}$ system was dominated by nZVI, which could release ferrous ions to promote the decomposition of hydrogen peroxide to generate free radicals; $\mathrm{Fe}_{3} \mathrm{O}_{4}$ not only could increase the surface area and improve the dispersion and stability of particles, but also could take part in the degradation processes of pollutants by releasing ferrous and ferric ions from the inner structure. The synergistic effect of nZVI and $\mathrm{Fe}_{3} \mathrm{O}_{4}$ made the 2,4-D degradation efficiency in the $\mathrm{Fe}^{0} @ \mathrm{Fe}_{3} \mathrm{O}_{4} / \mathrm{H}_{2} \mathrm{O}_{2}$ system greater than that either of them alone.

\subsection{Degradation Products and Mechanism of 2,4-D in the $\mathrm{Fe}^{0} @ \mathrm{Fe}_{3} \mathrm{O}_{4} / \mathrm{H}_{2} \mathrm{O}_{2}$ System}

\subsubsection{Changes of Ferrous/Ferric Ions Concentration}

As demonstrated in Figure 8, the concentration of $\mathrm{Fe}^{2+}$ in the $\mathrm{Fe}^{0} @ \mathrm{Fe}_{3} \mathrm{O}_{4} / \mathrm{H}_{2} \mathrm{O}_{2}$ system increased from 0 to $0.31 \mathrm{mg} / \mathrm{L}$ in the first $10 \mathrm{~min}$ and then gradually decreased; a second increase appeared at about $30 \mathrm{~min}$ followed by a tendency to decline. Throughout, the ferrous curve floated in a concentration range; even the top one reached only $0.171 \mathrm{mg} / \mathrm{L}$. This might be because the existence of the oxide layer on the surface of the catalyst, which would limit the dissolution of nZVI and slow down the release of $\mathrm{Fe}^{2+}$ at the beginning of the reaction. As the oxide layer gradually dissolved and fell off, fresh nZVI 
was exposed in the solution, and the generation of ferrous iron could also be accelerated. However, the released $\mathrm{Fe}^{2+}$ would quickly react with hydrogen peroxide to convert to $\mathrm{Fe}^{3+}$, resulting in the low ferrous concentration in solution.

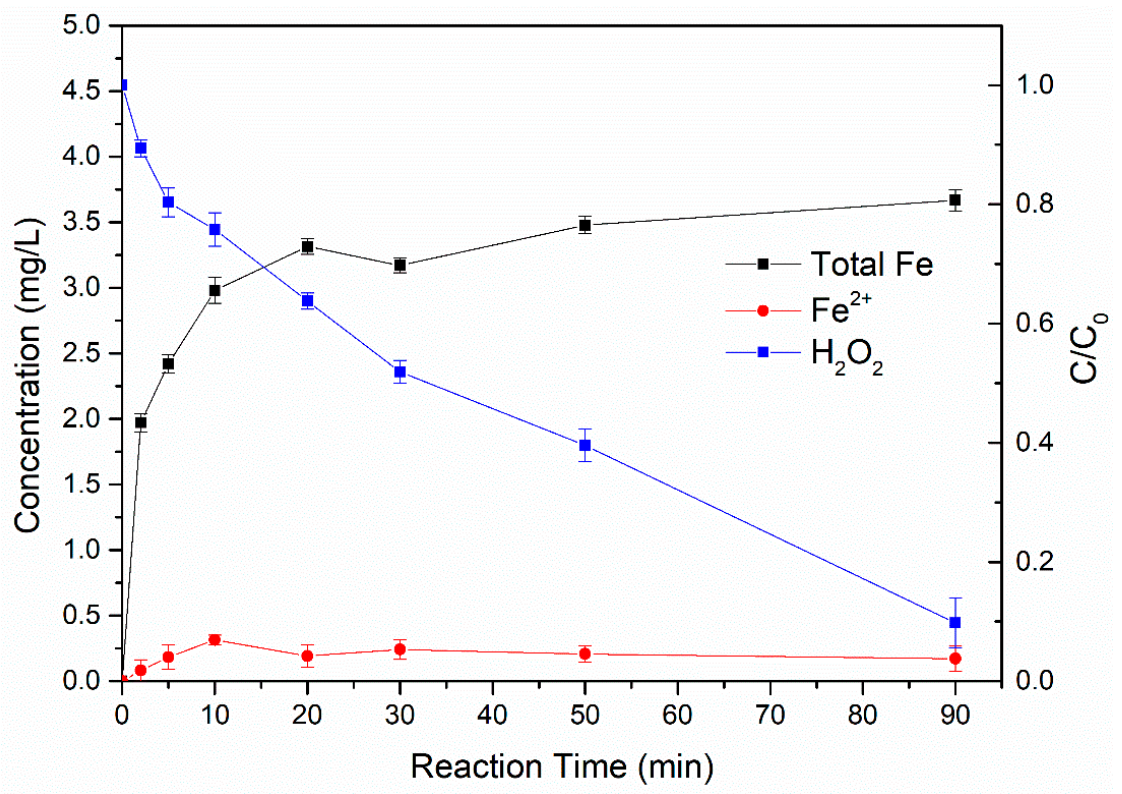

Figure 8. Changes of $\mathrm{Fe}^{2+}$ and $\mathrm{Fe}^{3+}$ concentrations in the $\mathrm{Fe}^{0} @ \mathrm{Fe}_{3} \mathrm{O}_{4} / \mathrm{H}_{2} \mathrm{O}_{2}$ system $\left([2,4-\mathrm{D}]_{0}=5.0 \mathrm{mg} / \mathrm{L}\right.$, $\left.\left[\mathrm{Fe}^{0} @ \mathrm{Fe}_{3} \mathrm{O}_{4}\right]_{0}=0.5 \mathrm{~g} / \mathrm{L}, \mathrm{H}_{2} \mathrm{O}_{2}=1 \mathrm{mM}, \mathrm{pH}=5.0 \pm 0.2, \mathrm{~T}=30^{\circ} \mathrm{C}\right)$.

The concentration of total iron rapidly increased to $3.3 \mathrm{mg} / \mathrm{L}$ in the first $20 \mathrm{~min}$ and then decreased slightly; finally, it remained at $3.66 \mathrm{mg} / \mathrm{L}$ at the end of the reaction. Ferrous ions released during the reaction of $\mathrm{nZVI}$ and hydrogen peroxide were quickly consumed and converted into ferric iron, leading to the rapid rise of the total iron concentration. Meanwhile, the resultant $\mathrm{Fe}^{3+}$ could react with $\mathrm{Fe}^{0}$ and be transferred into $\mathrm{Fe}^{2+}$ again, realizing the cycle of $\mathrm{Fe}^{2+} / \mathrm{Fe}^{3+}$. In addition, the precipitation of $\mathrm{Fe}^{3+}$ would cause a decrease in the total iron concentration. According to the concentration curve of hydrogen peroxide, it could be seen that the decomposition rate of hydrogen peroxide was very fast in the first $30 \mathrm{~min}$ and then gradually slowed down, which reflected that the reaction between $\mathrm{Fe}^{0}$ and $\mathrm{Fe}^{2+}$ with hydrogen peroxide was also changed from rapid to slow, which was consistent with the concentration change of total iron and the degradation of 2,4-D. After $90 \mathrm{~min}$, the residual hydrogen peroxide in the solution was less than $10 \%$, indicating that $\mathrm{Fe}^{0} @ \mathrm{Fe}_{3} \mathrm{O}_{4}$ nanoparticles could efficiently catalyze the decomposition of the hydrogen peroxide.

\subsubsection{Identification of the Predominant Radical Species Generated in the $\mathrm{Fe}^{0} @ \mathrm{Fe}_{3} \mathrm{O}_{4} / \mathrm{H}_{2} \mathrm{O}_{2}$ System}

In order to find the major active species responsible for the degradation of 2,4-D and have a better understanding of the mechanism in the $\mathrm{Fe}^{0} @ \mathrm{Fe}_{3} \mathrm{O}_{4} / \mathrm{H}_{2} \mathrm{O}_{2}$ heterogeneous Fenton system, $\mathrm{KI}$ and n-butanol were selected as free radical quenching agents in this study to eliminate the hydroxyl radicals. In the heterogeneous Fenton process, there were surface-bound hydroxyl radicals and free hydroxyl radicals in solution. KI mainly reacted with the former ones, while excessive n-butanol could quench both of them [38,39]. It can be seen from Figure 9 that the addition of KI and n-butanol had a significant inhibitory effect on the degradation of 2,4-D. Compared with the condition without quenching agents, the removal efficiency of the target pollutants was reduced from $100 \%$ to $23 \%$ and $10 \%$, respectively, confirming the fact that the oxidative degradation of 2,4-D mainly depends on hydroxyl radicals' oxidation. It was calculated that only about $13 \%$ of the target pollutant removal could be attributed to the free hydroxyl radicals in solution, and the rest of 2,4-D (about 77\%) was reduced by surface-bound hydroxyl radicals. Meanwhile, without the existence of two types of hydroxyl radicals, there was still a $23 \%$ removal of the target pollutant be achieved, indicating that apart from the adsorption of the 
$\mathrm{Fe}^{0} @ \mathrm{Fe}_{3} \mathrm{O}_{4}$ particles, other active ingredients with high redox capacity like active $[\mathrm{H}]$ might exist in the $\mathrm{Fe}^{0} @ \mathrm{Fe}_{3} \mathrm{O}_{4} / \mathrm{H}_{2} \mathrm{O}_{2}$ system, which could also degrade a small amount of 2,4-D.

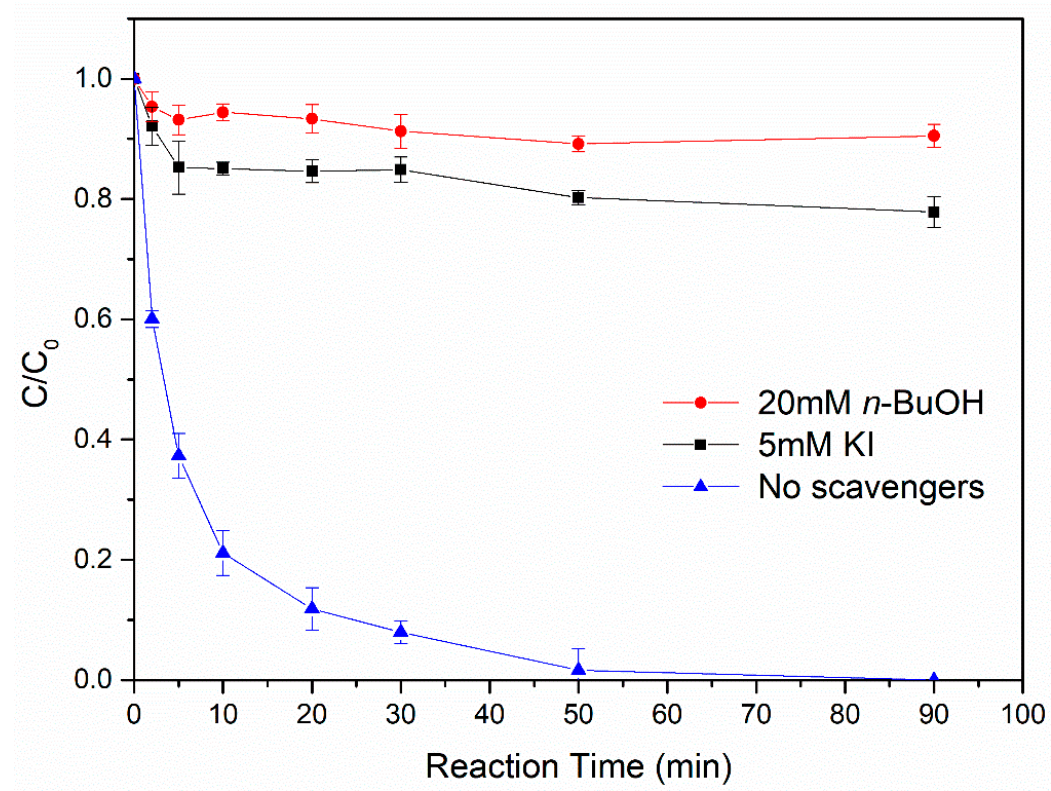

Figure 9. Effect of radical scavengers on the degradation of 2,4-D in the $\mathrm{Fe}^{0} @ \mathrm{Fe}_{3} \mathrm{O}_{4} / \mathrm{H}_{2} \mathrm{O}_{2}$ system $\left([2,4-\mathrm{D}]_{0}=5.0 \mathrm{mg} / \mathrm{L},\left[\mathrm{Fe}^{0} @ \mathrm{Fe}_{3} \mathrm{O}_{4}\right]_{0}=0.5 \mathrm{~g} / \mathrm{L}, \mathrm{H}_{2} \mathrm{O}_{2}=1 \mathrm{mM}, \mathrm{pH}=5.0 \pm 0.2, \mathrm{~T}=30^{\circ} \mathrm{C}\right)$.

\subsubsection{Degradation Products and Mineralization of 2,4-D}

Changes of total organic carbon (TOC) and chloride ion concentration during the degradation of 2,4-D in the $\mathrm{Fe}^{0} @ \mathrm{Fe}_{3} \mathrm{O}_{4} / \mathrm{H}_{2} \mathrm{O}_{2}$ system were detected to study the mineralization and dechlorination of pollutants and shown in Figure 10. Unlike the rapid reduction of 2,4-D, the decreasing of TOC tended to be slower. In the end, no 2,4-D was detected in the solution, while $34 \%$ of TOC remained. It can be inferred that although 2,4-D could be quickly degraded and removed in this system, it had not been completely mineralized. This might be due to the formation and remaining refractory organic substances in the solution. At the same time, the final concentration of $\mathrm{Cl}^{-}(0.038 \mathrm{mM})$ was lower than the theoretical calculated value of complete dechlorination $(0.046 \mathrm{mM})$, suggesting that there were other chlorine-containing intermediate products generated in the degradation process of the pollutants, which were difficult to be effectively degraded or required a longer reaction time. Although this heterogeneous Fenton system did not completely mineralize 2,4-D within $90 \mathrm{~min}$, the elimination of TOC also exceeded $66 \%$, and it was observed that the TOC decreasing curve had a downward trend, indicating the potential for further mineralization in this system. 


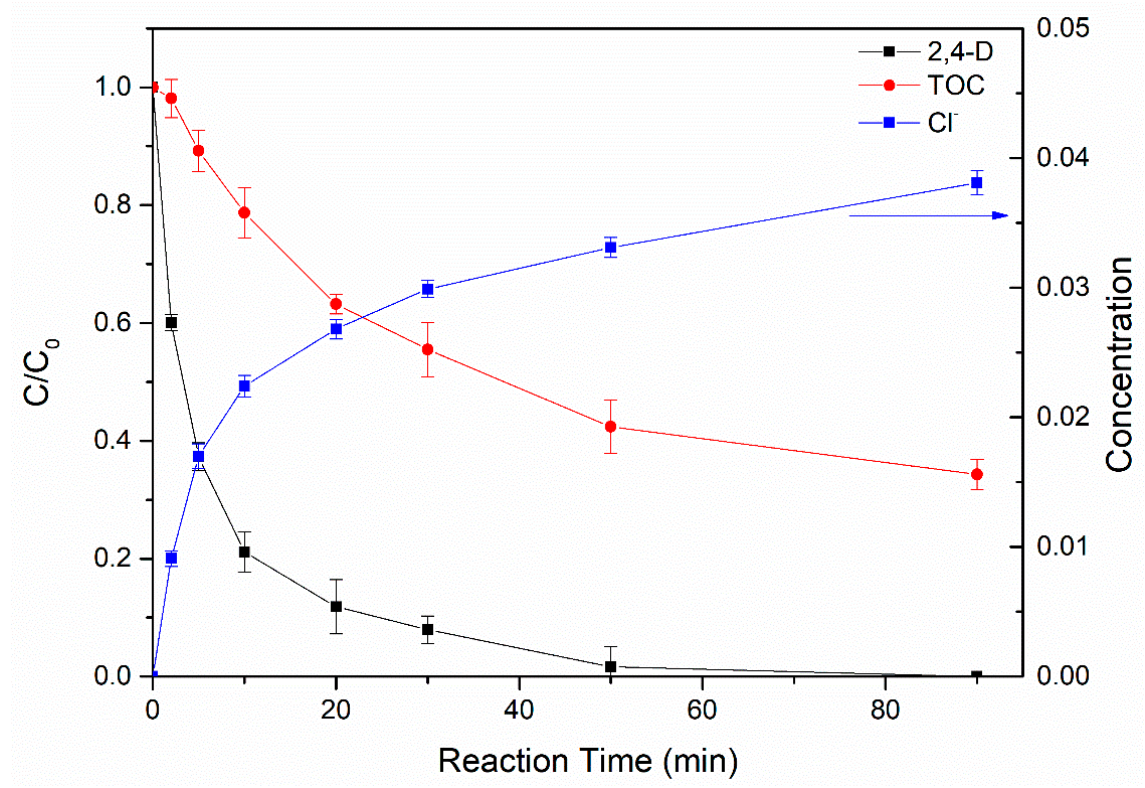

Figure 10. Changes of TOC and $\mathrm{Cl}^{-}$concentrations with the degradation of 2,4-D $\left([2,4-\mathrm{D}]_{0}=5.0 \mathrm{mg} / \mathrm{L}\right.$, $\left.\left[\mathrm{Fe}^{0} @ \mathrm{Fe}_{3} \mathrm{O}_{4}\right]_{0}=0.5 \mathrm{~g} / \mathrm{L}, \mathrm{H}_{2} \mathrm{O}_{2}=1 \mathrm{mM}, \mathrm{pH}=5.0 \pm 0.2, \mathrm{~T}=30^{\circ} \mathrm{C}\right)$.

GC-MS was used to investigate the intermediate products formed during the degradation of 2,4-D in the $\mathrm{Fe}^{0} @ \mathrm{Fe}_{3} \mathrm{O}_{4} / \mathrm{H}_{2} \mathrm{O}_{2}$ system. Figure 11 depicts the main degradation products in the solution after $20 \mathrm{~min}$. By comparing the peak value and response intensity of the products, it could be seen that 2,4-dichlorophenol (2,4-DCP) was one of the most important degradation products of 2,4-D. In addition, a certain concentration of 2,6-dichlorophenol (2,6-DCP) and some small-molecule organic acids such as formic acid, acetic acid, glycolic acid, and glyoxylic acid were generated during the reaction. Meanwhile, a small amount of 4,6-dichlororesorcinol (4,6-DCR), 2-chlorohydroquinone (2-CHQ), and 2-chloro-1,4-dichlorobenzoquinone (2-CBQ) was generated.

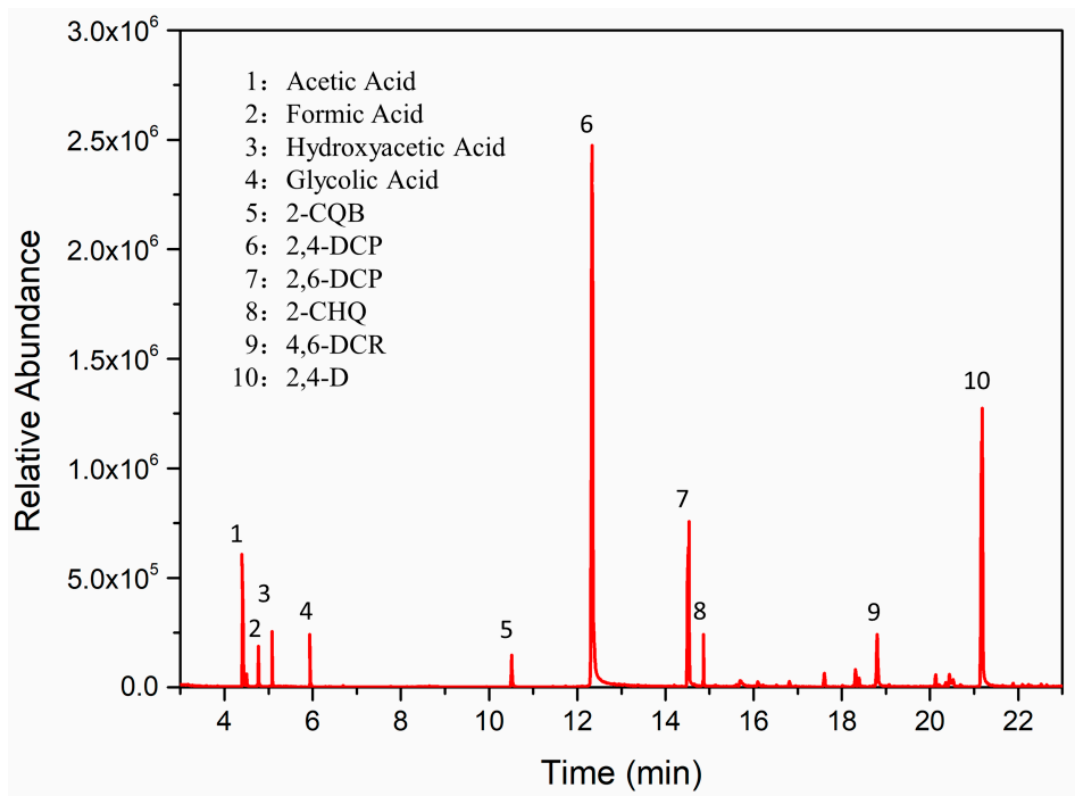

Figure 11. GC-MS spectra of intermediate products formed in 2,4-D degradation ([2,4-D $]_{0}$ $\left.=5.0 \mathrm{mg} / \mathrm{L},\left[\mathrm{Fe}^{0} @ \mathrm{Fe}_{3} \mathrm{O}_{4}\right]_{0}=0.5 \mathrm{~g} / \mathrm{L}, \mathrm{H}_{2} \mathrm{O}_{2}=1 \mathrm{mM}, \mathrm{pH}=5.0 \pm 0.2, \mathrm{~T}=30{ }^{\circ} \mathrm{C}\right) .2-\mathrm{CBQ}$, 2-chloro-1,4-dichlorobenzoquinone; 2,4-DCP, 2,4-dichlorophenol; 4,6-DCR, 4,6-dichlororesorcinol. 
With the degradation of 2,4-D, 2,4-DCP gradually formed and accumulated in the solution. This could be further degraded into 4,6-DCR and 2-CHQ through the electrophilic attack and dechlorinative substitution of the hydroxyl radical. 4,6-DCR was subsequently decomposed into small molecule organic acids through oxidation or dechlorination, while 2-CHQ would be hydroxylated and converted into 2-CBQ, then become small molecule organic acid in the same way as 4,6-DCR. Furthermore, through a series of reactions, oxalic acid and formic acid could be generated from the degradation of glycolic acid. All the small molecule organic acids formed above could be decomposed into $\mathrm{H}_{2} \mathrm{O}$ and $\mathrm{CO}_{2}$, completing the mineralization of the target pollutant.

\subsubsection{Mechanism of 2,4-D Degradation in the $\mathrm{Fe}^{0} @ \mathrm{Fe}_{3} \mathrm{O}_{4} / \mathrm{H}_{2} \mathrm{O}_{2}$ System}

In the $\mathrm{Fe}^{0} @ \mathrm{Fe}_{3} \mathrm{O}_{4} / \mathrm{H}_{2} \mathrm{O}_{2}$ system, it was the generated hydroxyl radicals (surface-bound hydroxyl radicals and free hydroxyl radicals) that were mainly attributed to the degradation of 2,4-D, and their formation could be realized by the decomposition of hydrogen peroxide, which was motivated by the surface-bound $\equiv \mathrm{Fe}(\mathrm{II})$ and the free $\mathrm{Fe}^{2+}$ ions released from the oxidation of zero-valent iron. As shown in Equations (11)-(17), it was possible that there were two types of interface mechanisms in this system. One was the homogeneous Fenton reaction initiated by dissolved $\mathrm{Fe}^{2+} / \mathrm{Fe}^{3+}$ in solution, and the other one was the heterogeneous Fenton reaction involving the $\equiv \mathrm{Fe}$ (II) on the surface of the catalyst particle $[12,13,40]$.

$$
\begin{gathered}
\mathrm{Fe}^{0}+2 \mathrm{H}^{+} \rightarrow \mathrm{Fe}^{2+} / \equiv \mathrm{Fe}(\mathrm{II})+\mathrm{H}_{2} \\
\mathrm{Fe}^{0}+\mathrm{O}_{2}+2 \mathrm{H}^{+} \rightarrow \mathrm{Fe}^{2+} / \equiv \mathrm{Fe}(\mathrm{II})+\mathrm{H}_{2} \mathrm{O}_{2} \\
\mathrm{Fe}^{0}+\mathrm{H}_{2} \mathrm{O}_{2} \rightarrow \mathrm{Fe}^{2+} / \equiv \mathrm{Fe}(\mathrm{II})+\mathrm{OH}+\mathrm{OH}^{-} \\
\equiv \mathrm{Fe}(\mathrm{II})+\mathrm{H}_{2} \mathrm{O}_{2} \rightarrow \equiv \mathrm{Fe}(\mathrm{III})-\mathrm{OH}+\mathrm{OH} \\
\mathrm{Fe}^{2+}+\mathrm{H}_{2} \mathrm{O}_{2} \rightarrow \mathrm{Fe}^{3+}+\mathrm{OH}^{-}+\mathrm{OH} \\
\equiv \mathrm{Fe}(\mathrm{III})+\mathrm{H}_{2} \mathrm{O}_{2} \rightarrow \equiv \mathrm{Fe}(\mathrm{II})+\mathrm{H}^{+}+\mathrm{HO}_{2} \\
\mathrm{Fe}^{3+}+\mathrm{H}_{2} \mathrm{O}_{2} \rightarrow \mathrm{Fe}^{2+}+\mathrm{H}^{+}+\mathrm{HO}_{2}
\end{gathered}
$$

Both pathways could generate hydroxyl radicals for the effective degradation of 2,4-D. However, in terms of the free radical inhibition experiments, the heterogeneous way accounted for a much larger proportion of the removal than the homogeneous one, and surface-bound hydroxyl radicals were the major active species in the system to remove 2,4-D. Due to the stability of most iron-based catalytic materials, the releasing of ferrous ions was limited. Free radicals involved in the oxidation of organic compounds were mainly generated through the heterogeneous Fenton reaction process. In summary, the two pathways of degrading 2,4-D in the $\mathrm{Fe}^{0} @ \mathrm{Fe}_{3} \mathrm{O}_{4} / \mathrm{H}_{2} \mathrm{O}_{2}$ system are shown in Figure 12. 


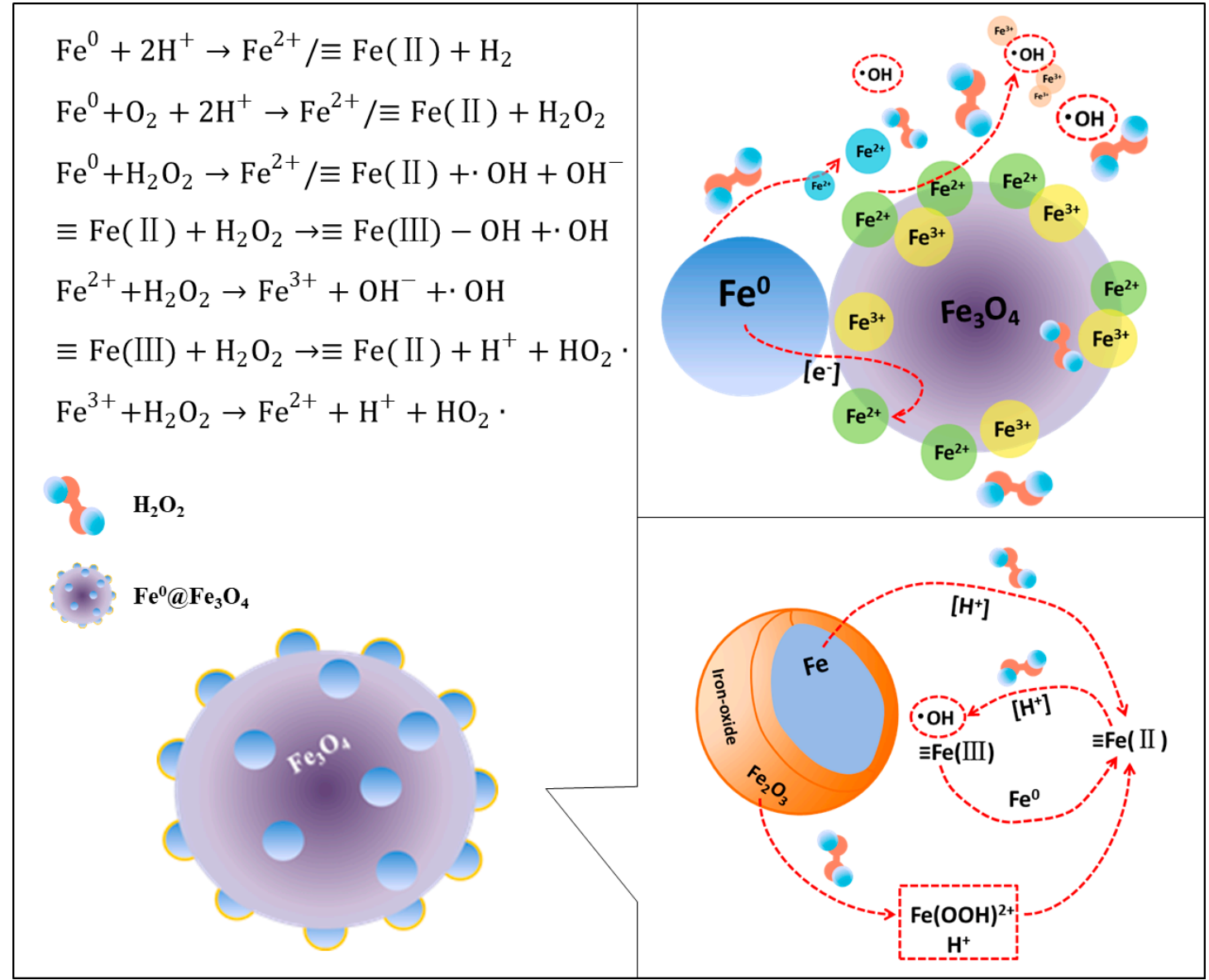

Figure 12. Possible mechanism for 2,4-D degradation in the $\mathrm{Fe}^{0} @ \mathrm{Fe}_{3} \mathrm{O}_{4} / \mathrm{H}_{2} \mathrm{O}_{2}$ system.

In the homogeneous Fenton process, nZVI oxidized and released $\mathrm{Fe}^{2+}$ into the solution, catalyzing the decomposition of hydrogen peroxide to generate hydroxyl radicals for 2,4-D degradation; in the heterogeneous Fenton-like process, nZVI particles were oxidized to form $\equiv \mathrm{Fe}$ (II) through electron transfer. Hydrogen peroxide diffusing from the solution to the surface of the $\mathrm{Fe}^{0} @ \mathrm{Fe}_{3} \mathrm{O}_{4}$ particles would be catalyzed by $\equiv \mathrm{Fe}$ (II) to generate surface-bound hydroxyl radicals. Simultaneously, the adsorption of the catalyst made 2,4-D accumulate on its surface and react with the generated hydroxyl radicals at the active sites to complete the degradation, then the degradation products again diffused back into the solution from the solid phase interface. It is worth noting that the $\mathrm{Fe}_{3} \mathrm{O}_{4}$ molecule has a special reverse spinel structure, which makes it possible for its structural $\mathrm{Fe}^{2+}$ and $\mathrm{Fe}^{3+}$ at the octahedral site to transpose, so it is conducive to the internal oxidation-reduction reaction of $\mathrm{Fe}^{2+} / \mathrm{Fe}^{3+}$. The electron transfer between ferric ions and ferrous ions endowed $\mathrm{Fe}_{3} \mathrm{O}_{4}$ with unique electromagnetic properties, and $\mathrm{Fe}_{3} \mathrm{O}_{4}$ could participate in the Fenton-like reaction through releasing of structural $\mathrm{Fe}^{2+} / \mathrm{Fe}^{3+}$, motivating the decomposition of hydrogen peroxide and the formation of free radicals, thereby enhancing the 2,4-D removal effect. However, compared with that of nZVI particles, the dissolution of magnetite was much slower and usually consumed more hydrogen peroxide and more time when $\mathrm{Fe}_{3} \mathrm{O}_{4}$ participated in the Fenton reaction as a catalyst alone. At the same time, under acidic conditions, there was a redox of $\mathrm{Fe}^{2+}(\equiv \mathrm{Fe}(\mathrm{II}))$ and $\mathrm{Fe}^{3+}(\equiv \mathrm{Fe}(\mathrm{III}))$, which could accelerate the regeneration of ferrous ions and was beneficial to the decomposition of hydrogen peroxide and the generation of free radical [41]. 


\section{Conclusions}

$\mathrm{Fe}^{0} @ \mathrm{Fe}_{3} \mathrm{O}_{4} \mathrm{NPs}$ was synthesized and successfully applied in the reduction of 2,4-D by constructing a heterogeneous Fenton-like system with hydrogen peroxide. It could adapt to a $\mathrm{pH}$ range from 3.0 to 6.5 , which was wider than the traditional Fenton process. The introduction of magnetite overcame the aggregation of nZVI and accelerated electron transfer. The modified catalyst with a better dispersity than single $\mathrm{nZVI}$ could remove $5 \mathrm{mg} / \mathrm{L}$ of 2,4-D effectively in $90 \mathrm{~min}$. Two possible interface mechanisms might exist in the $\mathrm{Fe}^{0} @ \mathrm{Fe}_{3} \mathrm{O}_{4} / \mathrm{H}_{2} \mathrm{O}_{2}$ system: one is the homogeneous Fenton reaction initiated by dissolved $\mathrm{Fe}^{2+} / \mathrm{Fe}^{3+}$ in solution, and the other one is the heterogeneous Fenton reaction involving the $\equiv$ Fe (II) on the surface of the catalyst particle. The hydroxyl radicals (especially the surface-bound one) generated during both of them could achieve the oxidative degradation and mineralization of 2,4-D effectively. This research put forward an easily available modified catalyst with strong adaptability for the rapid remediation of highly-chlorinated organic compounds including 2,4-D.

Author Contributions: Conceptualization, X.L.; methodology, X.L. and Y.M.; validation, X.L. and Y.M.; formal analysis, X.L.; investigation, X.L. and Y.L.; data curation, X.L.; writing, original draft preparation, X.L.; supervision, Q.Y. All authors read and agreed to the published version of the manuscript.

Funding: This work was funded by the Major Science and Technology Program for Water Pollution Control and Treatment of China (2015ZX07406005-001) and the Fundamental Research Funds for the Central Universities (2652018205).

Conflicts of Interest: The authors declare no conflict of interest. The funders had no role in the design of the study; in the collection, analyses, or interpretation of data; in the writing of the manuscript; nor in the decision to publish the results.

\section{References}

1. Boivin, A.; Amellal, S.; Schiavon, M.; Van Genuchten, M.T. 2,4-Dichlorophenoxyacetic acid (2,4-D) sorption and degradation dynamics in three agricultural soils. Environ. Pollut. 2005, 138, 92-99. [CrossRef] [PubMed]

2. Song, Y. Insight into the mode of action of 2, 4-dechlorophenoxyacetic acid (2,4-D) as an herbicide. J. Integr. Plant Biol. 2014, 56, 106-113. [CrossRef]

3. Garabrant, D.H.; Philbert, M.A. Review of 2,4-Dichlorophenoxyacetic Acid (2,4-D) Epidemiology and Toxicology. Crit. Rev. Toxicol. 2002, 32, 233-257. [CrossRef]

4. Chu, W.; Kwan, C.; Chan, K.; Chong, C. An unconventional approach to studying the reaction kinetics of the Fenton's oxidation of 2,4-dichlorophenoxyacetic acid. Chemosphere 2004, 57, 1165-1171. [CrossRef] [PubMed]

5. Atamaniuk, T.M.; Kubrak, O.I.; Storey, K.B.; Lushchak, V.I. Oxidative stress as a mechanism for toxicity of 2,4-dichlorophenoxyacetic acid (2,4-D): Studies with goldfish gills. Ecotoxicology 2013, 22, 1498-1508. [CrossRef] [PubMed]

6. Brillas, E. Mineralization of 2,4-D by advanced electrochemical oxidation processes. Water Res. 2000, 34, 2253-2262. [CrossRef]

7. Lee, C.; Keenan, C.R.; Sedlak, D.L. Polyoxometalate-Enhanced Oxidation of Organic Compounds by Nanoparticulate Zero-Valent Iron and Ferrous Ion in the Presence of Oxygen. Environ. Sci. Technol. 2008, 42, 4921-4926. [CrossRef]

8. Babuponnusami, A.; Muthukumar, K. A review on Fenton and improvements to the Fenton process for wastewater treatment. J. Environ. Chem. Eng. 2014, 2, 557-572. [CrossRef]

9. Pignatello, J.J.; Oliveros, E.; Mackay, A. Advanced Oxidation Processes for Organic Contaminant Destruction Based on the Fenton Reaction and Related Chemistry. Crit. Rev. Environ. Sci. Technol. 2006, 36, 1-84. [CrossRef]

10. Benatti, C.T.; da Costa, A.C.S.; Tavares, C.R.G. Characterization of solids originating from the Fenton's process. J. Hazard. Mater. 2009, 163, 1246-1253.

11. Chu, L.; Wang, J.; Dong, J.; Liu, H.; Sun, X. Treatment of coking wastewater by an advanced Fenton oxidation process using iron powder and hydrogen peroxide. Chemosphere 2012, 86, 409-414. [CrossRef] [PubMed]

12. Joo, S.H.; Feitz, A.J.; Sedlak, D.L.; Waite, T.D. Quantification of the Oxidizing Capacity of Nanoparticulate Zero-Valent Iron. Environ. Sci. Technol. 2005, 39, 1263-1268. [CrossRef] [PubMed] 
13. Xu, L.; Wang, J.L. A heterogeneous Fenton-like system with nanoparticulate zero-valent iron for removal of 4-chloro-3-methyl phenol. J. Hazard. Mater. 2011, 186, 256-264. [CrossRef]

14. Kim, Y.-H.; Carraway, E.R. Dechlorination of Pentachlorophenol by Zero Valent Iron and Modified Zero Valent Irons. Environ. Sci. Technol. 2000, 34, 2014-2017. [CrossRef]

15. Noubactep, C.; Carè, S. On nanoscale metallic iron for groundwater remediation. J. Hazard. Mater. 2010, 182, 923-927. [CrossRef]

16. Garbou, A.M.; Liu, M.; Zou, S.; Yestrebsky, C. Degradation kinetics of hexachlorobenzene over zero-valent magnesium/graphite in protic solvent system and modeling of degradation pathways using density functional theory. Chemosphere 2019, 222, 195-204. [CrossRef] [PubMed]

17. Kim, J.S.; Shea, P.J.; Yang, J.E.; Kim, J.-E. Halide salts accelerate degradation of high explosives by zerovalent iron. Environ. Pollut. 2007, 147, 634-641. [CrossRef]

18. Bae, S.; Lee, W. Influence of Riboflavin on Nanoscale Zero-Valent Iron Reactivity during the Degradation of Carbon Tetrachloride. Environ. Sci. Technol. 2014, 48, 2368-2376. [CrossRef]

19. Lv, X.; Li, H.; Ma, Y.; Yang, H.; Yang, Q. Degradation of Carbon Tetrachloride by nanoscale Zero-Valent Iron@ magnetic Fe3O4: Impact of reaction condition, Kinetics, Thermodynamics and Mechanism. Appl. Organomet. Chem. 2018, 32, 4139. [CrossRef]

20. Huang, R.; Fang, Z.; Yan, X.; Cheng, W. Heterogeneous sono-Fenton catalytic degradation of bisphenol A by Fe3O4 magnetic nanoparticles under neutral condition. Chem. Eng. J. 2012, 197, 242-249. [CrossRef]

21. Tan, L.; Lu, S.; Fang, Z.; Cheng, W.; Tsang, E.P. Enhanced reductive debromination and subsequent oxidative ring-opening of decabromodiphenyl ether by integrated catalyst of nZVI supported on magnetic Fe3O4 nanoparticles. Appl. Catal. B Environ. 2017, 200, 200-210. [CrossRef]

22. Chen, H.; Zhang, Z.; Feng, M.; Liu, W.; Wang, W.; Yang, Q.; Hu, Y. Degradation of 2,4-dichlorophenoxyacetic acid in water by persulfate activated with FeS (mackinawite). Chem. Eng. J. 2017, 313, 498-507. [CrossRef]

23. Lv, X.; Prastistho, W.; Yang, Q.; Tokoro, C. Application of nano-scale zero-valent iron adsorbed on magnetite nanoparticles for removal of carbon tetrachloride: Products and degradation pathway. Appl. Organomet. Chem. 2020, 34, e5592. [CrossRef]

24. Zhu, H.; Jia, Y.; Wu, X.; Wang, H. Removal of arsenic from water by supported nano zero-valent iron on activated carbon. J. Hazard. Mater. 2009, 172, 1591-1596. [CrossRef]

25. Fan, L.; Luo, C.; Sun, M.; Li, X.; Lu, F.; Qiu, H. Preparation of novel magnetic chitosan/graphene oxide composite as effective adsorbents toward methylene blue. Bioresour. Technol. 2012, 114, 703-706. [CrossRef] [PubMed]

26. Yamashita, T.; Hayes, P. Analysis of XPS spectra of Fe2+ and Fe3+ ions in oxide materials. Appl. Surf. Sci. 2008, 254, 2441-2449. [CrossRef]

27. Rivas, F.J.; Beltrán, F.J.; Frades, J.; Buxeda, P. Oxidation of p-hydroxybenzoic acid by Fenton's reagent. Water Res. 2001, 35, 387-396. [CrossRef]

28. Xu, X.R.; Li, X.Y.; Li, X.Z.; Li, H.B. Degradation of melatonin by UV, UV/H2O2, Fe2+/H2O2 and UV/Fe2+/H2O2 processes. Sep. Purif. Technol. 2009, 68, 261-266. [CrossRef]

29. Ma, Y.S.; Huang, S.T.; Lin, J.G. Degradation of 4-nitro phenol using the Fenton process. Water Sci. Technol. 2000, 42, 155-160.

30. Babuponnusami, A.; Muthukumar, K. Degradation of Phenol in Aqueous Solution by Fenton, Sono-Fenton and Sono-photo-Fenton Methods. Clean-Soil Air Water 2011, 39, 142-147. [CrossRef]

31. Kwan, W.P.; Voelker, B.M. Decomposition of Hydrogen Peroxide and Organic Compounds in the Presence of Dissolved Iron and Ferrihydrite. Environ. Sci. Technol. 2002, 36, 1467-1476. [CrossRef]

32. De La Plata, G.B.O.; Alfano, O.M.; Cassano, A.E. Decomposition of 2-chlorophenol employing goethite as Fenton catalyst II: Reaction kinetics of the heterogeneous Fenton and photo-Fenton mechanisms. Appl. Catal. B Environ. 2010, 95, 14-25. [CrossRef]

33. Lin, S.H.; Lo, C.C. Fenton process for treatment of desizing wastewater. Water Res. 1997, 31, $2050-2056$. [CrossRef]

34. Liu, C.-C.; Tseng, D.-H.; Wang, C.-Y. Effects of ferrous ions on the reductive dechlorination of trichloroethylene by zero-valent iron. J. Hazard. Mater. 2006, 136, 706-713. [CrossRef] [PubMed]

35. Lookman, R.; Bastiaens, L.; Borremans, B.; Maesen, M.; Gemoets, J.; Diels, L. Batch-test study on the dechlorination of 1, 1, 1-trichloroethane in contaminated aquifer material by zero-valent iron. J. Contam. Hydrol. 2004, 74, 133-144. [CrossRef] 
36. Zhou, T.; Li, Y.; Lim, T.-T. Catalytic hydrodechlorination of chlorophenols by Pd/Fe nanoparticles: Comparisons with other bimetallic systems, kinetics and mechanism. Sep. Purif. Technol. 2010, 76, $206-214$. [CrossRef]

37. Wang, N.; Zheng, T.; Zhang, G.; Wang, P. A review on Fenton-like processes for organic wastewater treatment. J. Environ. Chem. Eng. 2016, 4, 762-787. [CrossRef]

38. Pham, A.L.-T.; Lee, C.; Doyle, F.M.; Sedlak, D.L. A Silica-Supported Iron Oxide Catalyst Capable of Activating Hydrogen Peroxide at Neutral pH Values. Environ. Sci. Technol. 2009, 43, 8930-8935. [CrossRef] [PubMed]

39. Navalón, S.; Alvaro, M.; Garcia, H. Heterogeneous Fenton catalysts based on clays, silicas and zeolites. Appl. Catal. B Environ. 2010, 99, 1-26. [CrossRef]

40. Sychev, A.Y.; Isak, V.G. Iron compounds and the mechanisms of the homogeneous catalysis of the activation of $\mathrm{O} 2$ and H2O2and of the oxidation of organic substrates. Russ. Chem. Rev. 1995, 64, 1105-1129. [CrossRef]

41. Wang, H.; Liang, H.S.; Chang, M.B. Chlorobenzene oxidation using ozone over iron oxide and manganese oxide catalysts. J. Hazard. Mater. 2011, 186, 1781-1787. [CrossRef]

Publisher's Note: MDPI stays neutral with regard to jurisdictional claims in published maps and institutional affiliations.

(C) 2020 by the authors. Licensee MDPI, Basel, Switzerland. This article is an open access article distributed under the terms and conditions of the Creative Commons Attribution (CC BY) license (http://creativecommons.org/licenses/by/4.0/). 